\title{
1 Successful conservation of global waterbird populations depends on effective
}

\section{governance}

Tatsuya Amano ${ }^{1,2}$, Tamás Székely ${ }^{3,4}$, Brody Sandel $^{5}$, Szabolcs Nagy ${ }^{6}$, Taej Mundkur ${ }^{6}$, Tom

Langendoen $^{6}$, Daniel Blanco ${ }^{7}$, Candan U. Soykan ${ }^{8}$, William J. Sutherland ${ }^{1}$

${ }^{1}$ Conservation Science Group, Department of Zoology, University of Cambridge, The David Attenborough Building, Pembroke Street, Cambridge, CB2 3QZ, UK.

${ }^{2}$ Centre for the Study of Existential Risk, University of Cambridge, 16 Mill Lane, Cambridge, CB2 1SG, UK.

${ }^{3}$ Milner Centre for Evolution, Department of Biology and Biochemistry, University of Bath, Bath BA2 7AY, UK.

${ }^{4}$ Department of Evolutionary Zoology, University of Debrecen, Debrecen, H-4010, Hungary.

${ }^{5}$ Section for Ecoinformatics and Biodiversity, Department of Bioscience, Aarhus University, Aarhus 8000 C, Denmark.

${ }^{6}$ Wetlands International Head Office, Horapark 9, 6717 LZ Ede, The Netherlands.

${ }^{7}$ Wetlands International Argentina, 25 de Mayo 75810 I, Buenos Aires 1002, Argentina.

${ }^{8}$ National Audubon Society, Conservation Science, 220 Montgomery St., Suite 1000, San Francisco, CA 94104, USA. 
Understanding global patterns of biodiversity change is crucial for conservation research, policies and practices. However, the lack of systematically collected data at a global level has limited our understanding of biodiversity changes and their local-scale drivers in most ecosystems. We address this challenge by focusing on wetlands, which are among the most biodiverse and productive environments ${ }^{1,2}$ providing essential ecosystem services ${ }^{3,4}$, but are also amongst the most seriously threatened ecosystems ${ }^{3,5}$. Using birds as an indicator taxon of wetland biodiversity, we model time-series abundance data for 461 waterbird species at 25,769 survey sites across the globe. We show that countries' effective governance is the strongest predictor of waterbird abundance changes as well as benefits of conservation efforts. Waterbirds are declining especially where governance is, on average, less effective, such as Western/Central Asia, sub-Saharan Africa and South America. Higher protected area coverage facilitates waterbird increases, but only in countries with more effective governance. Our findings highlight that sociopolitical instability can lead to biodiversity loss and also undermine the benefit of existing conservation efforts, such as the expansion of protected area coverage. Data deficiency in areas with less effective governance could cause an underestimation of the extent of biodiversity crisis. Alternative language abstracts are in Supplementary Information.

Quantifying global patterns of biodiversity change is essential for assessing anthropogenic impacts on biodiversity, conservation priorities and the effectiveness of conservation efforts $^{6,7}$. It has, therefore, been identified as a research priority by major international bodies $^{8,9}$. However, most taxa have serious gaps in the spatial extent and resolution covered 
by available data ${ }^{10}$, meaning our current view of global biodiversity change is limited to coarse-resolution patterns ${ }^{11}$ or data-rich countries ${ }^{12}$ and protected areas ${ }^{13}$. This has impeded the identification of hotspots of abundance losses and analysis of local-scale drivers of change at the global scale (see Supplementary Discussion).

Wetlands cover more than 1,280 million hectares of coastal, inland and human-made habitats globally ${ }^{3,14}$. Despite being highly biologically diverse and productive $e^{1,2}$, providing a range of crucial ecosystem functions and services ${ }^{1,3,4}$, wetlands have been degraded and lost more than any other ecosystems ${ }^{3}$. Yet the lack of appropriate data has hampered assessments of changes in wetland biodiversity globally.

Here we address this knowledge gap by examining waterbirds as an indicator taxon for assessing the status of biodiversity in wetland ecosystems. Waterbirds have a long history of systematic monitoring, providing a global dataset on abundance changes with unprecedented spatial extent and resolution ${ }^{15}$. Modelling the global data for waterbirds enabled us to test two fundamental questions that are rarely explored together: (i) where are global changes in species abundance concentrated? (ii) What explains changes in abundance at the community, species and population levels? For the second question we tested three types of hypothesised predictors: (i) anthropogenic impacts (represented by surface water change, economic and human population growth, agricultural expansion and climate change), (ii) conservation efforts and effectiveness (protected area coverage and governance), and (iii) biological characteristics of species (range size, migratory status and body size) (Extended Data Table 1). Our dataset included 2,463,403 count records in January/February for the past three decades on 461 waterbird species at 25,769 survey sites throughout the globe (Extended Data 
Fig. 1). Using a hierarchical Bayesian model we estimated the global distribution of changes in each species' abundance between 1990 and 2013 at $1^{\circ} \times 1^{\circ}$ resolution (Supplementary Data S1). We then summarised the changes at the three levels: mean changes in abundance across all waterbird species present in each grid cell (community-level changes), mean changes across all grid cells for each species (species-level changes) and changes in each grid cell for each species (population-level changes).

In most species, population-level changes in abundance varied markedly across geographical ranges. Some species that have increased in Europe showed severe declines in other regions (Fig. 1a-c) and vice versa (see Supplementary Data S1 for detail). Declines were especially pronounced in Africa for grebes, flamingos, pelicans, cormorants and shorebirds, in South America for shorebirds, storks, ibises, herons, waterfowl, cranes and rails, and in Western/Central Asia for waterfowl, cranes and rails (Fig. 1d-k).

We found major community-level abundance losses in areas where the biodiversity assessments have been limited, namely Western/Central Asia, sub-Saharan Africa and South America (Fig. 2a). On average, community-level declines were most severe in South America with $0.95 \%$ annual decline, equating to a $21 \%$ decline over 25 years (Fig. 2b). The decline was also severe, but predominantly inland, in Western/Central Asia. In contrast, Europe has experienced community-level increases. Note, however, that even in regions showing community-level increases, some species show severe abundance declines (Supplementary Data S1). These geographic patterns largely reflected patterns in migrants (Extended Data Fig. 2a). Non-migrants were observed only in some regions and showed declines in South America and part of East and South/Southeast Asia (Extended Data Fig. 2b). 
Of the eight explanatory variables representing anthropogenic impacts and conservation

efforts and effectiveness (see Methods), the strongest predictor of community-level abundance changes was countries' governance, i.e. how effectively the authorities of a country are exercising rules and enforcement mechanisms (Fig. 3a). Waterbird communities declined most in countries with less effective governance (e.g., Western/Central Asia and South America) and increased where it was more effective (e.g., Europe and North America, Fig. 3b). Governance also had an interactive effect with protected area coverage (Fig. 3a); extensive protected area coverage was associated with community-level increases, but only in areas with more effective governance (Extended Data Fig. 3a). Community-level declines were also pronounced in areas with higher water loss (e.g., Western/Central Asia ${ }^{16}$, Extended Data Fig. 3b).

To ascertain the causes of community-level changes, we partitioned the effects of explanatory variables into species-level (explaining variations in species-level changes between species) and population-level effects (explaining variations in population-level changes within species) for 293 species with sufficient data. Species-level changes were explained by the governance interaction with protected area coverage, gross domestic product (GDP) growth rates and body mass (Fig. 4a). Consistent with the community-level analysis, waterbird species with a higher coverage of protected areas increased more, but only in countries with more effective governance (Fig. 4c). Species in rapidly-growing economies and small-bodied species experienced greater declines (Fig. 4b, d). Governance was also the best predictor of population-level abundance changes, and most of the species with significant governance effects showed more population-level declines in areas with less effective 
governance (Extended Data Fig. 4 and Supplementary Discussion). These main conclusions were robust even when considering the correlation between governance and GDP per capita, and also to other sensitivity analyses (Extended Data Figs. 5-7, Supplementary Discussion).

Although our data are not spatially complete (Extended Data Fig. 1 and Supplementary Discussion), quantifying abundance changes within each species over large geographic areas uncovered novel hotspots of threats to bird species in wetland ecosystems. Earlier attempts did not identify biodiversity loss in, for example, Western/Central Asia, mainly because relevant data were unavailable (Supplementary Discussion). This spatial overlap between general data gaps and biodiversity loss could cause an underestimation of the ongoing biodiversity crisis, and the observation highlights the need for the global monitoring of species' abundances.

Our results highlight the importance of governance, presumably environmental aspects of governance (see Methods), in explaining global patterns in waterbird abundance changes. Local and regional studies have increasingly shown the environmental consequences of ineffective governance, such as species population declines ${ }^{17}$, deforestation ${ }^{18}$ and agricultural expansion ${ }^{19}$. Ineffective governance is often associated with the lack of environmental concerns, enforcement and investments ${ }^{20-22}$, leading to habitat loss and degradation. For example, unsustainable water management and dam construction in Western/Central Asia have caused drastic losses in permanent water over the past 30 years ${ }^{16}$. As a result, in Iran even some wetlands designated as protected areas have dried out ${ }^{23}$. Wetlands in central Argentina lack legal protection or regulations on water use, and many have shown considerable losses ${ }^{24}$. Ineffective hunting regulations can also explain abundance losses under 
ineffective governance. Political instability can weaken legal enforcement, thereby promoting unsustainable, often illegal, killing even in protected $\operatorname{areas}^{25}$. Numerous waterbird species are under severe hunting pressures in $\operatorname{Iran}^{23}$ and South America ${ }^{26}$. As wetland loss and hunting pressure are the main threats to most taxa, the hotspots of waterbird declines identified here merit urgent attention as areas of potential loss and degradation of wetland biodiversity, its functions and services.

This study also corroborates the benefits of protected areas in improving the conservation status of waterbird species, although these benefits are applicable only to those in countries with more effective governance. Our result gives a strong scientific basis at the global scale for the argument that effective governance is critical for protected areas in achieving their goals $^{27}$. Protected area coverage can be high even in developing countries with less effective governance (Extended Data Fig. 8). These protected areas, however, were insufficient for maintaining stable waterbird populations since 1990. Supporting this argument in wealthier regions with more effective governance, such as Western Europe, waterbirds have responded positively to the establishment of refuges and stronger legal protection under measures governed by the EU Birds Directive ${ }^{28}$.

Although the global coverage of protected areas continues to increase, our findings indicate that ineffective governance could undermine the benefits of such conservation efforts towards improving the status of global biodiversity. Levels of governance should be considered in the processes of identifying and prioritising areas of conservation importance, and distributing future efforts in research and funding. There is also an urgent need to measure, monitor, improve, and raise awareness about environmental governance globally. 
152 Global conservation conventions and specific agreements and frameworks could mobilise

153 international resources and expertise to strengthen effective governance. Governance is now

154 recognised to be essential for economic growth, social development and the eradication of

155 poverty and hunger ${ }^{4}$. Efforts to better understand and improve governance as well as to find

156 means of improving the effectiveness of specific measures when governance is weak

157 therefore provide common ground for conservationists, social scientists, policy makers and

158 the public for achieving sustainable development. 


\section{References}

1601 The Ramsar Convention on Wetlands, Wetland Ecosystem Services. (Available at: http://archive.ramsar.org/cda/en/ramsar-pubs-info-ecosystem-services/main/ramsar/1-30-

162 103\%5E24258_4000_0_,2011).

1632 Dudgeon, D. et al., Freshwater biodiversity: importance, threats, status and conservation 164 challenges. Biol. Rev. 81, 163-182 (2006).

1653 Millennium Ecosystem Assessment, Ecosystems and Human Well-Being: Wetlands and 166 Water Synthesis. (World Resources Institute, Washington, DC, 2005).

1674 United Nations General Assembly, Transforming Our World: the 2030 Agenda for $168 \quad$ Sustainable Development. Resolution Adopted by the General Assembly on 25 September 169 2015. (United Nations, New York, 2015).

1705 Young, H. S., McCauley, D. J., Galetti, M., and Dirzo, R., Patterns, causes, and 171 consequences of Anthropocene defaunation. Annu. Rev. Ecol. Evol. S. 47, 333-358 $172 \quad$ (2016).

1736 Balmford, A., Green, R. E., and Jenkins, M., Measuring the changing state of nature. 174 Trends Ecol. Evol. 18, 326-330 (2003).

1757 Margules, C. R. and Pressey, R. L., Systematic conservation planning. Nature 405, 243$176 \quad 253(2000)$.

1778 Convention on Biological Diversity, Decision X/2. The Strategic Plan for Biodiversity 178 2011-2020 and the Aichi Biodiversity Targets. (Secretariat of the Convention on 179 Biological Diversity, Montreal, 2010).

1809 Intergovernmental Platform on Biodiversity and Ecosystem Services, Generic Scoping 181 Report for the Regional and Subregional Assessments of Biodiversity and Ecosystem 
Services. (Intergovernmental Platform on Biodiversity and Ecosystem Services, Bonn,

183

184 2015).

10 Pimm, S. L. et al., The biodiversity of species and their rates of extinction, distribution, and protection. Science 344, 1246752 (2014).

11 WWF, Living Planet Report 2016. Risk and Resilience in a New Era. (WWF International, Gland, 2016).

12 Bowler, D. E. et al., Cross-realm assessment of climate change impacts on species' abundance trends. Nat. Ecol. Evol. 1, 0067 (2017).

13 Barnes, M. D. et al., Wildlife population trends in protected areas predicted by national socio-economic metrics and body size. Nat. Commun. 7, 12747 (2016).

14 The Ramsar Convention on Wetlands, Classification System for Wetland Type. (Available at: http://archive.ramsar.org/cda/en/ramsar-documents-guidelinesclassification-system/main/ramsar/1-31-105\%5E21235_4000_0_,2012).

15 Boere, G. C., Galbraith, C. A., and Stroud, D. A. eds., Waterbirds Around the World. (The Stationery Office, Edinburgh, 2006).

16 Pekel, J.-F., Cottam, A., Gorelick, N., and Belward, A. S., High-resolution mapping of global surface water and its long-term changes. Nature 540, 418-422 (2016).

17 Smith, R. J., Muir, R. D. J., Walpole, M. J., Balmford, A., and Leader-Williams, N., Governance and the loss of biodiversity. Nature 426, 67-70 (2003).

18 Umemiya, C., Rametsteiner, E., and Kraxner, F., Quantifying the impacts of the quality of governance on deforestation. Environ. Sci. Policy 13, 695-701 (2010).

19 Ceddia, M. G., Bardsley, N. O., Gomez-y-Paloma, S., and Sedlacek, S., Governance, agricultural intensification, and land sparing in tropical South America. P. Natl. Acad. Sci. USA. 111, $7242-7247$ (2014). 
20 Harring, N., Understanding the effects of corruption and political trust on willingness to make economic sacrifices for environmental protection in a cross-national perspective. Soc. Sci. Quart. 94, 660-671 (2013).

21 Sundström, A., Covenants with broken swords: corruption and law enforcement in governance of the commons. Global Environ. Change 31, 253-262 (2015). allocation of international aid for conservation. Conserv. Lett. 6, 12-20 (2013).

21323 Nourani, E., Kaboli, M., and Collen, B., An assessment of threats to Anatidae in Iran. $214 \quad$ Bird Conserv. Int. 25, 242-257 (2015).

215 Brandolin, P. G. and Blendinger, P. G., Effect of habitat and landscape structure on 216 waterbird abundance in wetlands of central Argentina. Wetl. Ecol. Manag. 24, 93-105 $217 \quad$ (2016).

21825 Brochet, A.-L. et al., Preliminary assessment of the scope and scale of illegal killing and 219 taking of birds in the Mediterranean. Bird Conserv. Int. 26, 1-28 (2016).

22026 Morrison, R. I. G. et al., Dramatic declines of semipalmated sandpipers on their major 221 wintering areas in the Guianas, Northern South America. Waterbirds 35, 120-134 (2012).

$222 \quad 27$ Lockwood, M., Good governance for terrestrial protected areas: a framework, principles 223 and performance outcomes. J. Environ. Manage. 91, 754-766 (2010).

22428 Kirby, J. S. et al., Key conservation issues for migratory land- and waterbird species on 225 the world's major flyways. Bird Conserv. Int. 18, S49-S73 (2008). 
Supplementary Information is linked to the online version of the paper at

www.nature.com/nature.

Acknowledgements We thank the coordinators, thousands of volunteer counters and

funders of the International Waterbird Census and Christmas Bird Count. See Supplementary

Notes for information on funders. Thanks to D. Unterkofler for preparing the NWC data, J.P.

González-Varo for his comments on an earlier draft, and M. Amano for all the long-standing

support. Silhouette images used in Fig. 1 are from PhyloPic (http://phylopic.org/): d: coursers, gulls, terns and auks (http://phylopic.org/image/966db6c3-7719-400d-af61-a2d671b293b8/), e: grebes and flamingos (http://phylopic.org/image/59be555f-7a96-4608-ab7135ab4f5e77e1/), f: loons and petrels (http://phylopic.org/image/ae2506e3-b97d-45d7-a3f91bfb1567e1b1/), g: pelicans, boobies and cormorants (http://phylopic.org/image/5e8fdb174d66-43b3-8fb0-d9db616ec431/), h: rails and cranes (http://phylopic.org/image/7f02b605c87b-4ec2-9e14-011f813c23a4/), i: shorebirds (http://phylopic.org/image/55ef874a-f0aa4796-9dec-416d43a9e833/), j: storks, ibises and herons (http://phylopic.org/image/870b21119eef-42e6-9e22-a8f67bbb444a/) and k: waterfowl (http://phylopic.org/image/3ceaa22b-8879-

$2434545-9 \mathrm{e} 32-425010 \mathrm{f3} 3 \mathrm{~cd} 4 /$ ). All maps in figures are based on version 1.4.0 of Natural Earth

244 data at 1:110 m scale (http://www.naturalearthdata.com/downloads/110m-culturalvectors/110m-admin-0-countries/). 
247 Author Contributions T.A., T.S. and W.J.S. designed the study. T.A., T.S., B.S., S.N.,

248 T.M., T.L., D.B. and C.S. collected and prepared data for the analyses. T.A. analysed the data 249 and wrote the paper. All authors discussed the results and commented on the manuscript at all 250 stages.

251

252 Author Information Reprints and permissions information is available at

253 www.nature.com/reprints. The authors declare no competing interests. Correspondence and

254 requests for materials should be addressed to T.A. (amatatsu830@ gmail.com). 

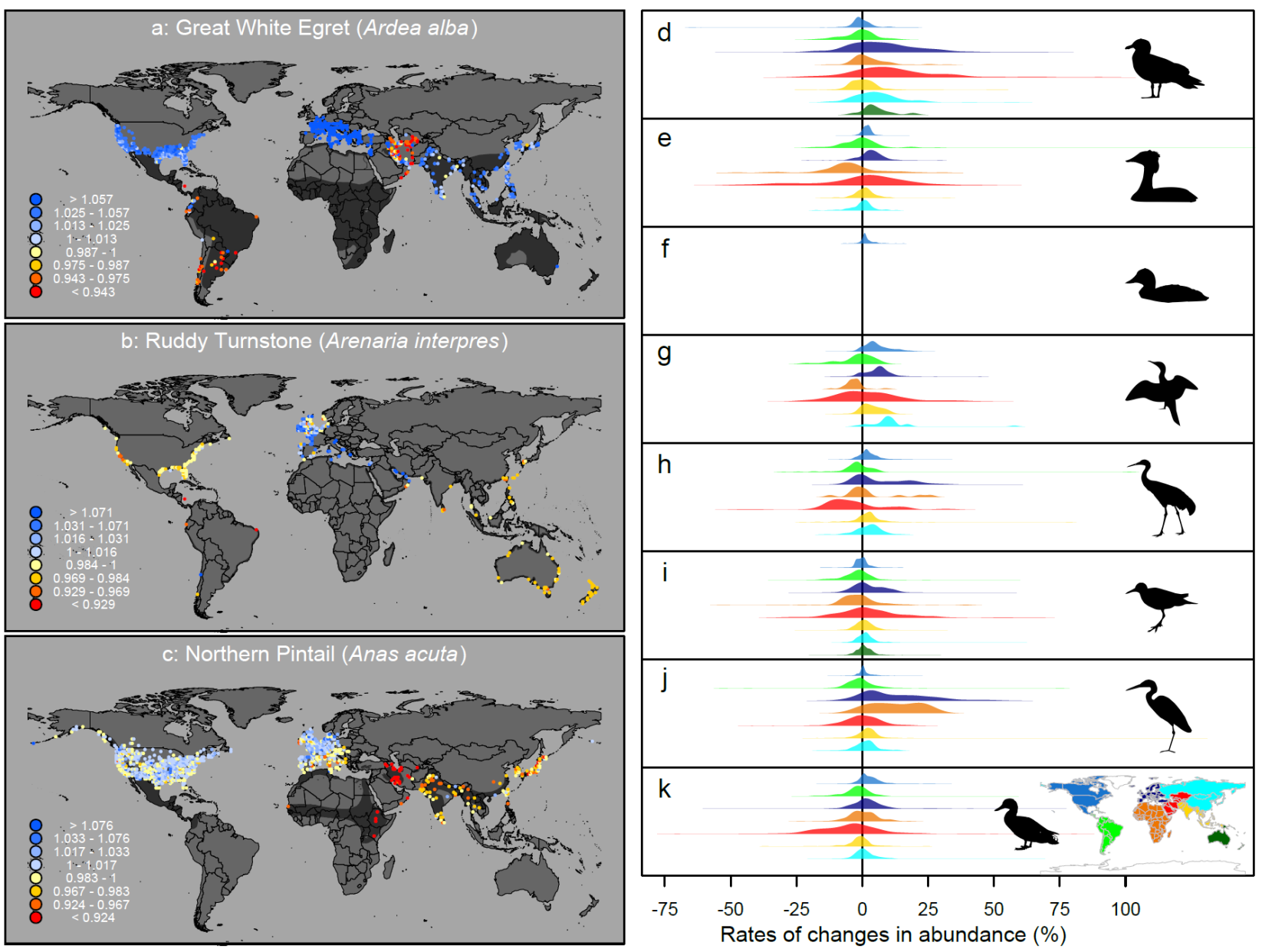

256 Fig. 1. Population-level changes in waterbird abundance in each $1^{\circ} \times 1^{\circ}$ grid cell between

2571990 and 2013. (a) Ardea alba, (b) Arenaria interpres and (c) Anas acuta as examples

258 (declines in red and increases in blue). Species' geographical ranges are shaded. (d-k)

259 Histograms show population-level changes for all species in each of the eight taxon at all grid

260 cells in each region (regions shown in the inserted map). See Methods for the definition of

261 each species group. 

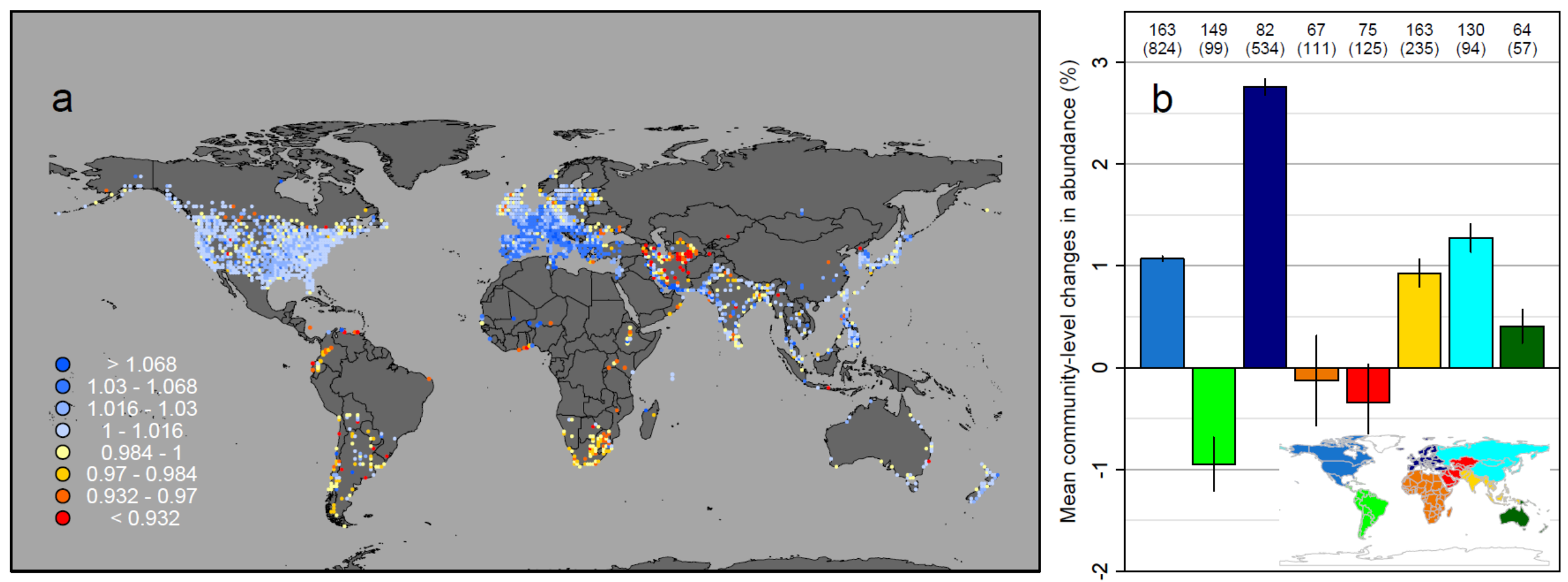

Fig. 2. Mean changes in abundance across 461 waterbird species (i.e., community-level changes) between 1990 and 2013 . (a) Global

distribution and (b) mean with 95\% confidence intervals across all grid cells in each region (regions shown in the inserted map). The numbers of species (and grid cells in parentheses) observed are also shown above bars. 

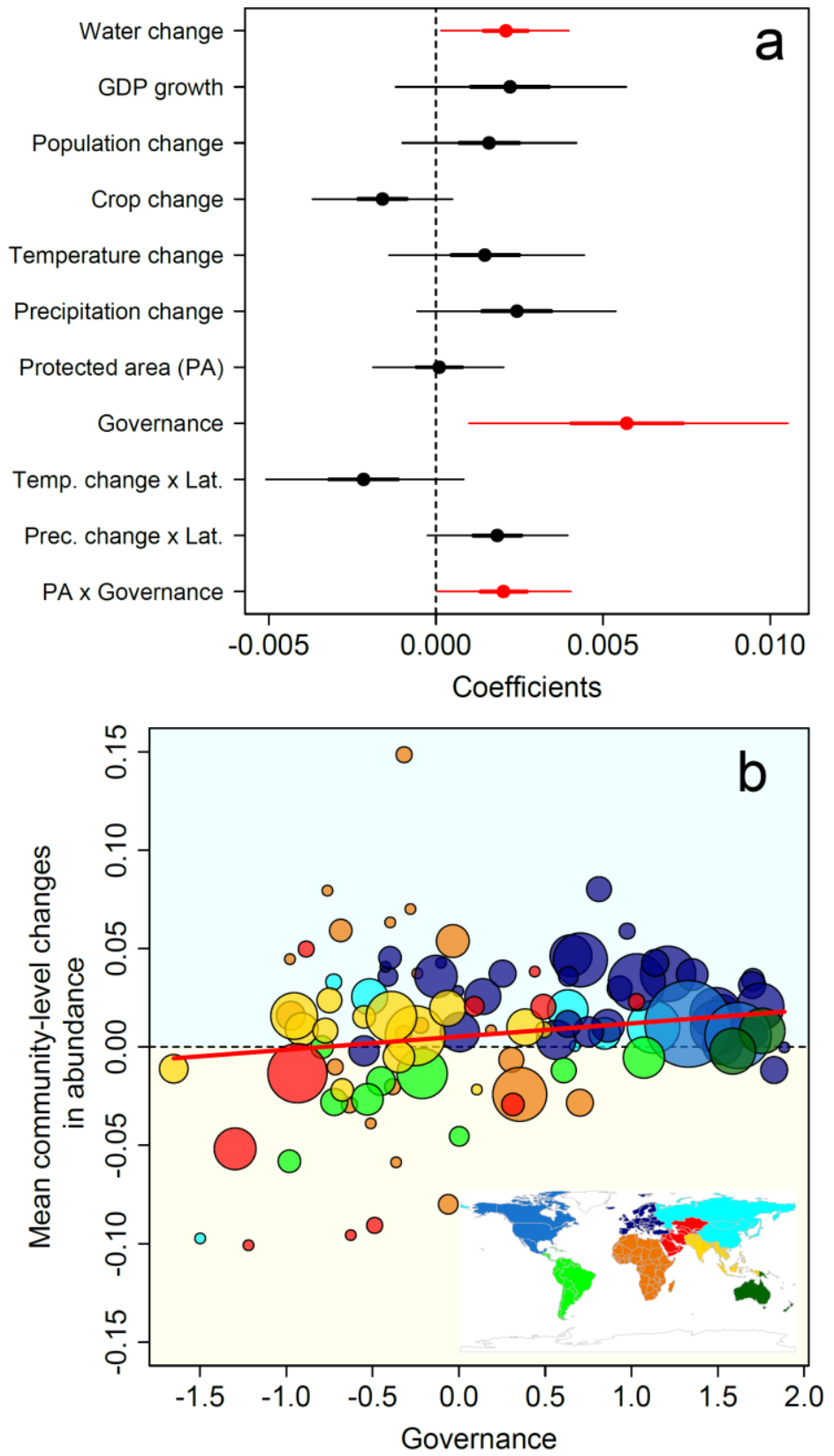

Fig. 3. Effects of predictors on community-level changes in waterbird abundance. (a)

268 Estimated coefficients in the multivariate analysis $(\mathrm{n}=2,079)$. Posterior medians with $95 \%$ and $26950 \%$ (thick lines) credible intervals are shown. Coefficients with 95\% credible intervals not overlapping with zero are shown in red. The coefficients represent the effect size of the

271 variables, which were standardised. (b) The relationship between community-level changes 272 and countries' governance, where each circle represents a country and its size is related to the 273 number of $1^{\circ} \times 1^{\circ}$ grid cells with estimates, with the color indicating the region. The regression 274 line is shown. 

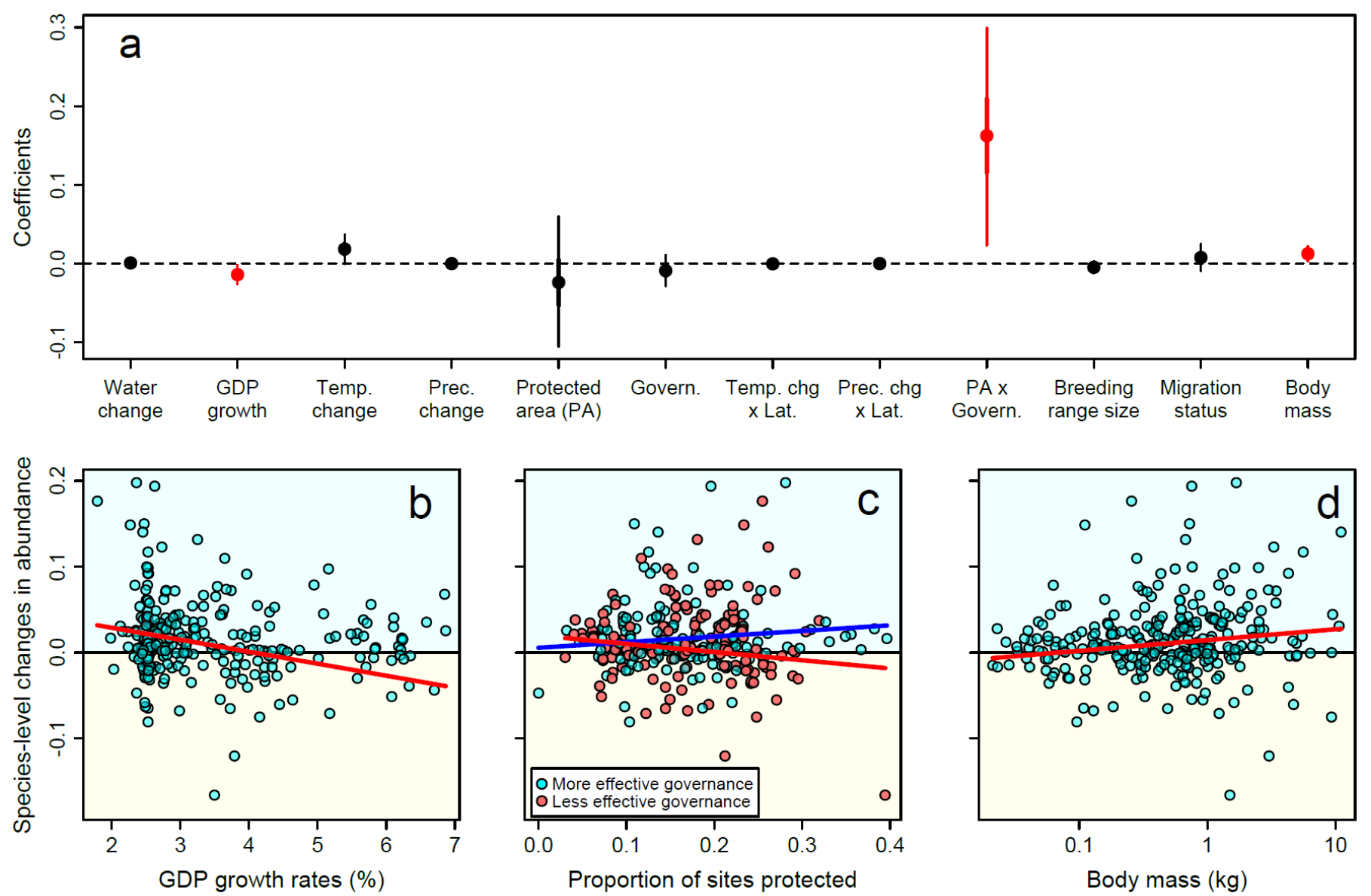

Fig. 4. Effects of predictors on species-level abundance changes in 293 waterbird species that were recorded in at least ten grid cells (see Supplementary Data S2 for details). (a) Estimated coefficients with 95\% and 50\% (thick lines) credible intervals (those not overlapping with zero shown in red) and the species-level relationship between abundance changes and (b) Gross Domestic Product (GDP) growth rates, (c)

proportion of sites covered by protected areas, (d) body mass. Values and regression lines for species in areas with more (above median) and less (below median) effective governance are shown in blue and red, respectively, in (c). 


\section{Data}

\section{Waterbird count data}

Data used in this study consisted of site-specific annual counts based on the International Waterbird Census (IWC) coordinated by Wetlands International ${ }^{29}$ and the Christmas Bird Count $(\mathrm{CBC})$ by the National Audubon Society in the USA ${ }^{30}$.

$$
\text { The IWC, launched in 1967, is a scheme for monitoring waterbird numbers, covering }
$$
more than 25,000 sites in over 100 countries with more than 15,000 observers. The coordination of the IWC is further divided into four regional schemes corresponding to the major migratory flyways of the world: the African-Eurasian Waterbird Census (AEWC), Asian Waterbird Census (AWC), Caribbean Waterbird Census (CWC) and Neotropical Waterbird Census (NWC). We did not use data from the Caribbean Waterbird Census, as, having started in 2010, it only provides short-term data. The survey methodology is essentially the same across the four regional schemes. Population counts are typically carried out once every year in mid-January. Additional counts are also conducted in other months, particularly in July in the Southern Hemisphere, but we only used counts in January and February for consistency. This means that our data from the Northern Hemisphere are for non-breeding populations while those in the Southern Hemisphere also include some breeding populations. In each country that is covered by the survey, national coordinators manage an inventory of wetland sites (hereafter, survey sites), including sites of international- or national-level recognition (e.g., Ramsar sites, Important Bird Areas, national parks etc.). Each survey site is generally defined by boundaries so that observers know precisely which areas are to be covered in the surveys. The observers consist of a wide variety of volunteers, but national coordinators usually train them using materials produced by Wetlands International 
to ensure the quality of count data. Survey sites (normally up to a few $\mathrm{km}^{2}$ ) are typically surveyed by about two observers for up to four hours, while larger sites can require a group of observers working over several days. The time of survey on any given day depends on the type of survey sites: inland sites are normally surveyed during the morning or late afternoon whereas coastal sites are surveyed over the high tide period (mangrove areas and nearby mudflats are, however, covered during low tides). Surveys cover waterbirds, which are defined as bird species that are ecologically dependent on wetlands ${ }^{29}$. Counts are usually made by scanning flocks of waterbirds with a telescope or binoculars and counting each species. Zero counts are not always recorded, and thus are inferred using a set of criteria (see Methods for more detail). Count records, together with associated information, are submitted to the national coordinators, who compile the submitted records, check their validity and submit those records to Wetlands International. See ${ }^{29,39}$ for more details on survey methodology.

As the IWC does not cover North America, we also used data based on the CBC, which has been conducted annually since 1900, and now includes over 2,400 count circles (defined as survey sites in this study) and involves more than 70,000 observers each year ${ }^{73}$. Each CBC consists of a tally of all bird species detected within $24.1 \mathrm{~km}$ in diameter, on a single day between 14th December and 5th January. The majority of circles (and most historical data) are from the US and Canada. Observers join groups that survey subunits of the circle during the course of the day using a variety of transportation methods (mostly on foot, or in a car, but can include boats, skis, or snowmobiles). The number of observers and the duration of counts vary among circles and through time. The total number of survey hours per count has been recorded as a covariate to account for the variable duration of and participation in the count.

328 We only used records on waterbird species in this paper. 
We compiled data from each scheme by species, except for data based on the African-

330 Eurasian Waterbird Census, where data had already been stored by flyway within each

331 species $^{31}$. As data based on the Neotropical Waterbird Census are only available after 1990,

332 we only used post-1990 data for other regions as well. The latest records were in 2013.

333 Although the data included 487 waterbird species, we excluded species with 20 or fewer

334 records from the analyses, and this has resulted in 461 species being analysed in this study

335 (see Supplementary Data S2 for the full list of species). For the IWC data, we generated zero

336 counts using an established approach ${ }^{31}$. In this approach, we first established a list of all

337 species observed in each country, and assumed a zero count of any species that were on the

338 list but not recorded at a particular site on a particular day if the site was surveyed on that day,

339 as shown by the presence of any other species' record(s), and if no multi-species code related

340 to the species (e.g., Anatinae spp. for species of the genus Anas) was recorded for the site-date

341 combination. We projected all survey sites onto a Behrmann equal-area cylindrical projection

342 and assigned them to grid cells with a grain size of $96.49 \mathrm{~km}$, or approximately $1^{\circ}$ at $30^{\circ} \mathrm{N} / \mathrm{S}$.

343 When visualising the estimated abundance changes (e.g., Figs. 2b and 3b), the North and

344 South American regions correspond to the regions covered by the CBC and NWC,

345 respectively. The regions covered by the AEWC and AWC were further divided into a total of

346 six regions based on socio-economic and ecological differences: Europe, Africa and

347 Western/Central Asia (AEWC), and South/Southeast Asia, East Asia and Russia, and Oceania 348 (AWC).

Explanatory variables

351 To explain variations in waterbird abundance changes over space and species, we first set up

352 multiple hypotheses based on earlier studies and identified explanatory variables that 
represent those hypotheses (Extended Data Table 1). We aggregated all the explanatory variables but those on species characteristics to the same $1^{\circ} \times 1^{\circ}$ grid cells.

As measures of governance we used the Worldwide Governance Indicators, which summarise six broad dimensions of governance: Voice and Accountability, Political Stability and Absence of Violence, Government Effectiveness, Regulatory Quality, Rule of Law, and Control of Corruption ${ }^{32}$. A study of six South American countries ${ }^{19}$ found that proenvironmental behaviours are associated with environmental aspects of governance rather than conventional dimensions of governance represented by the Worldwide Governance Indicators. At the global scale, however, the mean of the Worldwide Governance Indicators was strongly correlated with the Environmental Performance Index (EPI) ${ }^{33}$, one of the indicators of environmental governance used in the study ${ }^{19}(r=0.71, \mathrm{n}=180)$. This indicates that the Worldwide Governance Indicators are also a good predictor of environmental aspects of governance at the global scale. Further, the EPI consists of multiple indicators, some of which are directly related to our measures of conservation efforts, such as terrestrial protected areas and species protection. We thus decided not to use the EPI in our analysis, as using it together with the coverage of protected areas in our analysis could result in redundancies.

In the World Database on Protected Areas, not every protected area has information on designation years. Thus we calculated the proportion of sites located within any protected area, assuming that it also reflects the proportion of sites covered by protected areas designated at least before 2013 (the latest survey year of count data used in this study). To examine the sensitivity of our conclusions to this assumption, we also calculated, as the most conservative approach, the proportion of sites covered only by protected areas that are known to have been designated before 1990 (the oldest survey year), and conducted the same 
analyses using the variable and presented the results in Extended Data Fig. 5 and Supplementary Discussion. When assessing the effectiveness of protected areas, confounding factors can mask or mimic the impacts of protected areas. We thus controlled for effects of potential drivers of abundance changes (listed in Extended Data Table 1) by including them, together with protected area coverage, in the same multivariate models.

Based on the Birdlife Data Zone (http://datazone.birdlife.org/home), the migratory status of the 461 species analysed in this study falls into four categories: full migrant, altitudinal migrant, nomadic and not a migrant. In this study we defined species categorised as full migrant or altitudinal migrant as migrants.

\section{Other data}

We derived information on generation length (in years) from the BirdLife Data Zone and the Red List category by the International Union for Conservation of Nature from the BirdLife Checklist of the Birds of the World ${ }^{34}$ for each species. Generation length was not available in five species, for which we used the mean values across all species in the same genus. We used generation length as well as the bird species distribution maps of the world ${ }^{35}$ for the visualisation of results (see the legend of Supplementary Data S1 for more detail). Species groups used in Fig. 1 are based on the IOC World Bird List ${ }^{36}$ : coursers, gulls, terns and auks (Alcidae, Glareolidae, Laridae and Stercorariidae), grebes and flamingos (Phoenicopteridae and Podicipedidae), loons and petrels (Gaviidae and Procellariidae), pelicans, boobies and cormorants (Anhingidae, Fregatidae, Pelecanidae, Phalacrocoracidae and Sulidae), rails and cranes (Aramidae, Gruidae and Rallidae), shorebirds (Burhinidae, Charadriidae, Dromadidae, Haematopodidae, Ibidorhynchidae, Jacanidae, Recurvirostridae, Rostratulidae and 
Scolopacidae), storks, ibises and herons (Ardeidae, Ciconiidae and Threskiornithidae), and waterfowl (Anatidae and Anhimidae).

\section{Statistical Analyses}

\section{Model for quantifying abundance changes}

To account for missing values, large observation errors and spatial structure in the data, we used a hierarchical Bayesian spatial model and quantified population-level changes in the abundance of each species within each $1^{\circ} \times 1^{\circ}$ grid cell. This model is an extension of the model developed and used to quantify waterbird abundance changes in earlier studies ${ }^{37,38}$, and based on the site effect for site $i$, overall year effect for year $t$ and the cell-specific year effect for grid cell $j$ and year $t$. The overall year effect $\beta_{t}$ is assumed to be affected by the year effect in the previous two years:

$$
\beta_{t} \sim \operatorname{Normal}\left(\beta_{t-1}+r\left(\beta_{t-1}-\beta_{t-2}\right), \sigma_{o}^{2}\right) \text {. }
$$

Here $\sigma_{o}^{2}$ is the variance of the overall year effect, $r$ ranges from 0 to 1 and determined the smoothness of the estimated curve: with $r=0$, the overall year effect is modelled as a simple random-walk process, while other values lead to a correlated random walk with different degrees of smoothness (a larger $r$ causes a more smoothed curve). The cell-specific year effect $\beta_{j(i), t}$ is drawn from a normal distribution with mean $\beta_{t}$ is as follows:

$$
\beta_{j(i), t} \sim \operatorname{Normal}\left(\beta_{t}, \sigma_{\beta}^{2}\right)
$$

Including the variance in the year effect $\sigma_{\beta}^{2}$ allows the model to account for variations in trends of population counts among grid cells. $j(i)$ indicates that grid cell $j$ includes site $i$. Assuming the same population trend across all sites within each grid cell, the mean count $\mu_{i, t}$ 
in site $i$ in grid cell $j$ and year $t$ is modelled with the cell-specific year effect $\beta_{j(i), t}$, the site effect $\alpha_{i}$, the spatially correlated random effect $\gamma_{j(i)}$ and the overdispersion effect $\delta_{i, t}$ :

$$
\log \left(\mu_{i, t}\right)=\alpha_{i}+\beta_{j(i), t}+\gamma_{j(i)}+\delta_{i, t}
$$

Here, $\alpha_{i}$ and $\delta_{i, t}$ are drawn from a mean zero normal distribution with variance $\sigma_{\alpha}^{2}$ and $\sigma_{\delta}^{2}$, respectively. $\gamma_{j(i)}$ is drawn from an intrinsic Gaussian conditional autoregressive (CAR) prior distribution:

$$
\gamma_{j(i)} \mid \gamma_{k} \sim \operatorname{Normal}\left(\frac{\sum_{j \neq k} w_{j, k} \gamma_{k}}{n_{j}}, \frac{\sigma_{\gamma}^{2}}{n_{j}}\right)
$$

where $w_{j, k}=1$ if grid cells $j$ and $k$ are neighbors, and 0 otherwise. $n_{j}$ is the total number of neighbors of grid cell $j$ and neighbors here are defined as those grid cells directly adjacent, including those diagonal. $\sigma_{\gamma}^{2}$ controls the amount of variation between the random effects. The observed count $y_{i, t}$ in site $i$ and year $t$ is assumed to derive from a Poisson distribution with mean $\mu_{i, t}$.

$$
\text { We assumed constant survey efforts over time in the IWC, as regular, standardised }
$$
surveys (constant methods, efforts and timing) are highly encouraged ${ }^{39}$ (also see Supplementary Discussion). However, survey efforts in the CBC are known to vary through time. Thus using the total number of survey hours per count as the measure of survey efforts, we explicitly accounted for the effort effect for the CBC data following ${ }^{40}$ :

$$
\log \left(\mu_{i, t}\right)=\alpha_{i}+\beta_{j(i), t}+\gamma_{j(i)}+\delta_{i, t}+\frac{B\left(\left(\frac{\zeta_{i, t}}{\bar{\zeta}}\right)^{p}-1\right)}{p}
$$

Here $\zeta_{i, t}$ is the total number of survey hours per count and $\bar{\zeta}$ is the mean value of $\zeta_{i, t} . B$ and $p$ are parameters determining a range of relationships between effort and the number of birds counted $^{40}$. To test if accounting for survey efforts can change the conclusions of this paper, 
we also applied the model without the effort effect to the $\mathrm{CBC}$ data and compared the estimated rate of abundance change within each grid cell between the models for each of the 159 species with more than two grid cells. The estimated spatial patterns in abundance changes by the two models were highly correlated (median Pearson's $r=0.99$, minimum $r=$ 0.88), indicating the validity of the model without the effort effect used for the IWC data. Further discussions on the potential effects of temporal changes in survey efforts are provided in Supplementary Discussion.

We applied the models to count data of each species at the regional population level. For example, count data on Eurasian wigeon Mareca penelope are separately compiled as five different populations: three (northwest European, Black Sea/Mediterranean, and southwest Asian/northeast African) in the African-Eurasian Waterbird Census, one in the Asian Waterbird Census, and one in the CBC. In this case, we applied the models separately to each of the five populations. As the result, we analysed 775 regional populations of 461 species (see Supplementary Data S2 for the full list of species). For 38 regional populations where no grid cells with count records were adjacent to each other, we simply dropped the spatially correlated random effect $\gamma_{j(i)}$ from equations (3) and (5). For 32 regional populations with only one grid cell that includes more than one survey site, we dropped $\gamma_{j(i)}$ and also replaced the cell-specific year effect $\beta_{j(i), t}$ with the overall year effect $\beta_{t}$. For 22 regional populations with only one survey site, we applied a generalised linear model with a Poisson distribution, using observed counts as the response variable and years as the explanatory variable, and used the estimated slope as the rate of abundance change. 
Using only grid cells with, on average, four or more non-zero records per site, we fitted the models to the data with the Markov chain Monte Carlo (MCMC) method in WinBUGS 1.4.3 $3^{41}$ and the R2WinBUGS package ${ }^{42}$ in $\mathrm{R} 3.3 .2^{43}$. Prior distributions of parameters were set as non-informatively as possible, so as to produce estimates similar to those generated by a maximum likelihood method. We used Gamma distributions with mean of 1 and variance of 100 for the inverses of ${\sigma_{o}}^{2}, \sigma_{\beta}^{2}, \sigma_{\alpha}^{2}$ and $\sigma_{\delta}^{2}$ and $\sigma_{\gamma}^{2}$, normal distributions with mean of 0 and variance of 100 for $\beta_{1}, \beta_{2}$ and $B$, a beta distribution with mean of 0.5 and variance of 0.083 ( $\alpha$ $=\beta=1$, which is a uniform distribution, for $r$, and a uniform distribution on the interval [-4, 4] for $p$ following an earlier study ${ }^{44}$. Each MCMC algorithm was initially run with three chains with different initial values for 300,000 iterations with the first 200,000 discarded as burn-in and the remainder thinned to one in every 20 iterations to save storage space. Model convergence was checked with R-hat values ${ }^{45}$. If the models did not converge with the initial conditions, we increased iterations up to 5,000,000 (with the first 1,000,000 discarded and the remainder thinned to one in every 800). We decided to remove grid cells where parameter estimates did not converge even with the increased iterations, although the number of removed cells was very small (median 2.5 grid cells in 20 out of the $775(2.6 \%)$ regional populations).

To estimate the population-level change in abundance (since 1990) of each species in a particular grid cell, we first regressed the estimates of the cell-specific year effect $\beta_{j(i), t}$ in every posterior sample against years. To account for uncertainty in slope estimates in this regression, we derived for every posterior sample a slope estimate from a normal distribution with the mean of the estimated mean slope and standard deviation of the standard error of the 
slope. We then calculated the mean, median, variance and 2.5 and 97.5 percentiles of the estimated slopes from all posterior samples. We aggregated all estimates by species based on the definition by the BirdLife International ${ }^{34}$. We used the mean and 2.5 and 97.5 percentiles of the estimated slopes for creating species-level maps (Fig. 1a-c and Supplementary Data S1). To calculate community-level changes in abundance (Fig. 2a) and those for different migratory status (Extended Data Fig. 2), we used the mean slopes across all species, or all species in a particular group, observed in each grid cell, weighted by the inverse of slope variance in each species to account for uncertainties. To further calculate mean communitylevel changes in each region (Fig. 2b), we used the mean of the community-level changes across all grid cells in each region, weighted by the inverse of associated variance.

\section{Driver analysis}

We first tested correlations among the nine spatial explanatory variables in $2,0791^{\circ} \times 1^{\circ}$ grid cells with abundance change estimates (Extended Data Table 2). GDP per capita and governance showed a relatively strong correlation $(r=0.76)$. Thus considering that GDP growth rates are another measure of economic growth, we decided to exclude GDP per capita from the main analyses but instead test its effect in a separate set of analyses where governance was replaced with GDP per capita. Here considering the hypothesised non-linear relationship between GDP per capita and species abundance changes (Extended Data Table 1), we used linear and quadratic terms of GDP per capita. We presented the results with GDP per capita in Extended Data Fig. 5 and Supplementary Discussion. 
To identify factors associated with waterbird abundance changes at the community, species, and population levels, we conducted two types of analyses, both of which were implemented with WinBUGS 1.4.3 and the R2WinBUGS package in R 3.3.2.

In the first analysis, where the response variable was community-level changes in abundance within each grid cell (Fig. 2a), we used a CAR model:

$$
\mu_{i}=\alpha+\boldsymbol{\beta} \boldsymbol{X}_{\boldsymbol{i}}+\gamma_{i}
$$

where the community-level change $r_{i}$ in cell $i$ was assumed to derive from a normal distribution with mean $\mu_{i}$ and variance $\sigma_{\mu}^{2} \cdot \boldsymbol{\beta}$ represents the vector of regression coefficients and $\boldsymbol{X}_{i}$ that of explanatory variables. Based on the hypotheses shown in Extended Data Table 1, we used eight explanatory variables in each grid cell: surface water change, GDP growth rates, changes in human population density, crop area, temperature, and precipitation, protected area coverage, and governance. We also tested three interaction terms between latitudes and temperature change and also latitudes and precipitation change, as population responses to temperature and precipitation can vary along the latitudes ${ }^{46}$, and governance and protected area coverage, as governance can affect the effectiveness of conservation efforts ${ }^{47}$. All explanatory variables were standardised before model fitting. $\gamma_{i}$ is the spatially-correlated random effect using an intrinsic Gaussian CAR prior distribution with variance $\sigma_{\gamma}{ }^{2}$, as described in equation (4). Again prior distributions of parameters were set as noninformatively as possible; we used Gamma distributions with mean of 1 and variance of 1000 for the inverse of $\sigma_{\mu}{ }^{2}$ and $\sigma_{\gamma}{ }^{2}$, normal distributions with mean of 0 and variance of 1000 for $\beta_{j}$, and an improper uniform distribution (i.e., a uniform distribution on an infinite interval) for the intercept $\alpha$ as recommended ${ }^{48}$. Each MCMC algorithm was run with three chains with different initial values for 1,000,000 iterations with the first 500,000 discarded as burn-in and 
the remainder thinned to one in every 100 iterations to save storage space. Model convergence was checked with R-hat values.

Next for 293 species observed at ten or more grid cells, we adopted the within-subject centring approach ${ }^{49}$ under a hierarchical modelling framework to explicitly distinguish species-level effects (explaining variations in species-level abundance changes between species) and population-level effects (explaining variations in population-level abundance changes within species) of explanatory variables. In this model the species effect $\mu_{s}$, representing the species-level change in abundance of species $s$, is drawn from a normal distribution with mean of $v_{s}$ and variance of ${\sigma_{v}}^{2} \cdot v_{s}$ is further modelled with species-level explanatory variables:

$$
v_{s}=\alpha+\sum_{k=1}^{9} \beta_{B k} \bar{x}_{k, S}+\sum_{k=10}^{12} \beta_{B k} z_{k, S}+\eta_{s}
$$

where $\alpha$ is the global intercept and $\beta_{B k}$ represents the species-level effect. $\bar{x}_{k, s}$ is the mean of spatial explanatory variable $k$ across all grid cells where species $s$ was recorded. Note that even if the estimated species-level abundance changes are biased due to geographical biases in available grid cells, they are correctly matched up with $\bar{x}_{k, s}$, as the calculation of both variables is based on the same set of grid cells. The spatial explanatory variables used were based on the hypotheses in Extended Data Table 1, but we dropped changes in human population density and crop area, as these were least influential in the analysis of communitylevel population changes and also in a preliminary analysis of this model. Thus we used the remaining six explanatory variables (surface water change, GDP growth rates, changes in temperature and precipitation, protected area coverage, and governance) and the same three interaction terms as in the community-level analysis. $z_{k, s}$ represents three explanatory 
that accounts for phylogenetic dependence among species and is drawn from a multivariate normal distribution ${ }^{50,51}$ :

$$
\begin{aligned}
& \eta_{s} \sim \operatorname{MVN}\left(\mathbf{0}, \delta^{2} \Sigma_{\lambda}\right), \\
& \Sigma_{\lambda}=\lambda \Sigma+(1-\lambda) \mathbf{I}
\end{aligned}
$$

where $\Sigma$ is a scaled variance-covariance matrix calculated from an ultrametric phylogenetic tree. By scaling $\Sigma$ to a height of one, we can interpret $\delta^{2}$ as the residual variance ${ }^{50}$. For the strength of phylogenetic signal to vary, we also incorporated Pagel's $\lambda^{52,53}$ into the matrix in equation (9) with the identity matrix $\mathbf{I}$. Here $\lambda$ is a coefficient that multiplies the off-diagonal elements of $\Sigma$ and a $\lambda$ close to zero implies that the phylogenetic signal in the data is low, suggesting independence in the error structure of the data points, whereas a $\lambda$ close to one suggests a good agreement with the Brownian Motion evolution model and thus suggests correlation in the error structure ${ }^{50,53}$. To incorporate uncertainties ${ }^{54}$ in phylogenetic trees in the calculation of $\Sigma$, we used a sample of 100 trees from a comprehensive avian phylogeny ${ }^{55}$ as the prior distribution for our analysis ${ }^{50}$. More specifically, one of the 100 trees was randomly drawn in each iteration and used for the calculation of $\Sigma$.

The population-level change in abundance $r_{s, i}$ of species $s$ in grid cell $i$ was then assumed to derive from a normal distribution with mean $\mu_{s, i}$ and variance $\sigma_{\mu}^{2}$, where $\mu_{s, i}$ is modelled using the species effect $\mu_{s}$ :

$$
\mu_{s, i}=\mu_{s}+\sum_{j=1}^{6} \beta_{W_{s, j}}\left(x_{j, i}-\bar{x}_{j, s}\right)+\gamma_{s, i}
$$

Here $\beta_{W s, j}$ represents the population-level effect for species $s$, explaining within-species variations in population-level abundance changes $\left(\mu_{s, i}-\mu_{s}\right)$ by within-species variations in explanatory variables $\left(x_{j, i}-\bar{x}_{j, s}\right)$, where $x_{j, i}$ is explanatory variable $j$ in grid cell $i$ and $\bar{x}_{j, s}$ is 
the mean of $x_{j}$ for species $s$. The species-specific $\beta_{W s, j}$ is the random effect each governed by hyper-parameters as:

$$
\beta_{W_{s, j}} \sim \operatorname{Normal}\left(h \beta_{W_{j}}, \sigma_{\beta_{W_{j}}}^{2}\right) .
$$

For population-level effects we used the same six explanatory variables (surface water change, GDP growth rates, changes in temperature and precipitation changes, protected area coverage and governance). $\gamma_{s, i}$ accounts for spatial autocorrelation within each species and is drawn from an intrinsic Gaussian CAR prior distribution with variance $\sigma_{\gamma_{s}}^{2}$, as in equation (4).

As non-informative prior distributions, we used a Gamma distribution with mean of 1 and variance of 100 for $\sigma_{v}{ }^{2}, \delta^{2}, \sigma_{\mu}{ }^{2}, \sigma_{\beta_{W_{j}}}^{2}$ and $\sigma_{\gamma_{s}}^{2}$, a uniform distribution on the interval $[0,1]$ for $\lambda$, normal distributions with mean of 0 and variance of 100 for $\alpha, \beta_{B k}$, and $h \beta_{W j}$. Each MCMC algorithm was run with three chains with different initial values for 10,000 iterations with the first 5,000 discarded as burn-in and the remainder thinned to one in every two iterations to save storage space. Model convergence was checked with R-hat values. Due to differences in the definition of species between the two sources used ${ }^{34,55}$, we combined two separate species defined in the BirdLife Checklist ${ }^{34}$ into one in four cases for this specieslevel analysis: Kentish plover Charadrius alexandrinus and snowy plover C. nivosus, common snipe Gallinago gallinago and Wilson's snipe G. delicata, European herring gull Larus argentatus and Arctic herring gull L. smithsonianus, and common moorhen Gallinula chloropus and common gallinule G. galeata.

\section{Data Availability}


The waterbird count data used in this study are collated and managed by Wetlands International and the National Audubon Society, and available on request. All the data on explanatory variables are freely available as specified in Extended Data Table 1.

599

600

\section{Code Availability}

601

All the R and WinBUGS codes used for the analyses are available from the corresponding

602 author upon request.

603

604 References

60529 Delany, S., Guidance on Waterbird Monitoring Methodology: Field Protocol for

$606 \quad$ Waterbird Counting. (Wetlands International, Wageningen, 2010).

60730 Dunn, E. H. et al., Enhancing the scientific value of the Christmas Bird Count. The Auk $608 \quad \mathbf{1 2 2}, 338-346(2005)$.

60931 van Roomen, M., van Winden, E., and van Turnhout, C., Analyzing Population Trends at 610 the Flyway Level for Bird Populations Covered by the African Eurasian Waterbird 611 Agreement: Details of a Methodology. (SOVON Dutch Centre for Field Ornithology, $612 \quad$ Nijmegen, 2011).

$613 \quad 32$ Kaufmann, D., Kraay, A., and Mastruzzi, M., The Worldwide Governance Indicators: 614 Methodology and Analytical Issues (September 2010). (World Bank Policy Research 615 Working Paper No. 5430. Available at: https://ssrn.com/abstract=1682130, 2010). 61633 Hsu, A. et al., 2016 Environmental Performance Index. (Yale University. Available at: 617 www.epi.yale.edu., New Haven, CT, 2016). 
$619 \quad$ (Available at:

620 http://www.birdlife.org/datazone/userfiles/file/Species/Taxonomy/BirdLife_Checklist_V 621 ersion_70.zip, 2014).

62235 BirdLife International and NatureServe, Bird Species Distribution Maps of the World. 623 (BirdLife International, Cambridge and NatureServe, Arlington, 2014).

62436 Gill, F. and Donsker, D. eds., IOC World Bird List (v 5.1). (Available at:

625 http://www.worldbirdnames.org/, 2015).

62637 Amano, T., Okamura, H., Carrizo, S. F., and Sutherland, W. J., Hierarchical models for 627 smoothed population indices: The importance of considering variations in trends of count 628 data among sites. Ecol. Indic. 13, 243-252 (2012).

62938 Amano, T., Székely, T., Koyama, K., Amano, H., and Sutherland, W. J., A framework for 630 monitoring the status of populations: An example from wader populations in the East 631 Asian-Australasian flyway. Biol. Conserv. 143, 2238-2247 (2010).

63239 van Roomen, M. et al., Waterbird and Site Monitoring Along the Atlantic Coast of 633 Africa: Strategy and Manual. (BirdLife International, Cambridge, Common Wadden Sea 634 Secretariat, Wilhelmshaven and Wetlands International, Wageningen, 2014).

63540 Link, W. A. and Sauer, J. R., Seasonal components of avian population change: joint 636 analysis of two large-scale monitoring programs. Ecology 88, 49-55 (2007).

63741 Lunn, D. J., Thomas, A., Best, N., and Spiegelhalter, D., WinBUGS - a Bayesian 638 modelling framework: concepts, structure, and extensibility. Stat. Comput. 10, 325-337 $639 \quad$ (2000).

64042 Sturtz, S., Ligges, U., and Gelman, A., R2WinBUGS: a package for running WinBUGS 641 from R. J. Stat. Softw. 12, 1-16 (2005). 
43 R Core Team, R: A Language and Environment for Statistical Computing. (R Foundation

66452 Pagel, M., Inferring the historical patterns of biological evolution. Nature 401, 877-884 $665 \quad$ (1999). 
666

53 Freckleton, R. P., Harvey, P. H., and Pagel, M., Phylogenetic analysis and comparative data: A test and review of evidence. Am. Nat. 160, 712-726 (2002).

668

54 Donoghue, M. J. and Ackerly, D. D., Phylogenetic uncertainties and sensitivity analyses in comparative biology. Philos. T. Roy. Soc. B 351, 1241-1249 (1996).

55 Jetz, W., Thomas, G. H., Joy, J. B., Hartmann, K., and Mooers, A. O., The global diversity of birds in space and time. Nature 491, 444-448 (2012).

56 Grossman, G. M. and Krueger, A. B., Economic growth and the environment. Q. J. Econ. 110, 353-377 (1995).

57 Cardillo, M. et al., Human population density and extinction risk in the world's carnivores. PLOS Biol. 2, 909-914 (2004).

58 McKee, J., Chambers, E., and Guseman, J., Human population density and growth validated as extinction threats to mammal and bird species. Hum. Ecol. 41, 773-778 (2013).

59 Center for International Earth Science Information Network - CIESIN - Columbia University and Centro Internacional de Agricultura Tropical - CIAT, Gridded Population of the World, Version 3 (GPWv3): Population Density Grid. (NASA Socioeconomic Data and Applications Center (SEDAC). Available at: http://dx.doi.org/10.7927/H4XK8CG2, Palisades, NY, 2005).

60 Green, R. E., Cornell, S. J., Scharlemann, J. P. W., and Balmford, A., Farming and the fate of wild nature. Science 307, 550-555 (2005).

61 Friedl, M. A. et al., MODIS Collection 5 global land cover: Algorithm refinements and characterization of new datasets. Remote Sens. Environ. 114, 168-182 (2010).

62 Stephens, P. A. et al., Consistent response of bird populations to climate change on two continents. Science 352, 84-87 (2016). 
690

63 Harris, I., Jones, P. D., Osborn, T. J., and Lister, D. H., Updated high-resolution grids of

691 monthly climatic observations - the CRU TS3.10 Dataset. Int. J. Climatol. 34, 623-642

$692 \quad$ (2014).

69364 Kleijn, D., Cherkaoui, I., Goedhart, P. W., van der Hout, J., and Lammertsma, D.,

694 Waterbirds increase more rapidly in Ramsar-designated wetlands than in unprotected

695 wetlands. J. App. Ecol. 51, 289-298 (2014).

$696 \quad 65$ Pavón-Jordán, D. et al., Climate-driven changes in winter abundance of a migratory

697 waterbird in relation to EU protected areas. Divers. Distrib. 21, 571-582 (2015).

69866 UNEP-WCMC and IUCN (2015), Protected Planet: The World Database on Protected

699 Areas (WDPA), June 2015, Cambridge, UK: UNEP-WCMC and IUCN. Available at:

$700 \quad$ www.protectedplanet.net.

70167 Mace, G. M. et al., Quantification of extinction risk: IUCN's system for classifying

702 threatened species. Conserv. Biol. 22, 1424-1442 (2008).

70368 Sanderson, F. J., Donald, P. F., Pain, D. J., Burfield, I. J., and van Bommel, F. P. J.,

704 Long-term population declines in Afro-Palearctiv migrant birds. Biol. Conserv. 131, 93-

$705 \quad 105$ (2006).

70669 Robbins, C. S., Sauer, J. R., Greenberg, R. S., and Droege, S., Population declines in

707 North American birds that migrate to the neotropics. P. Natl. Acad. Sci. USA. 86, 7658-

$708 \quad 7662(1989)$

70970 Pocock, M. J. O., Can traits predict species' vulnerability? A test with farmland

710 passerines in two continents. P. Roy. Soc. Lond. B: Bio. 278, 1532-1538 (2011).

71171 Owens, I. P. F. and Bennett, P. M., Ecological basis of extinction risk in birds: habitat

712 loss versus human persecution and introduced predators. P. Natl. Acad. Sci. USA. 97, 713 12144-12148 (2000). 
71472 Wilman, H. et al., EltonTraits 1.0: Species-level foraging attributes of the world's birds 715 and mammals. Ecology 95, 2027-2027 (2014).

71673 LeBaron, G. S., The 115th Christmas Bird Count. (National Audubon Society, New

717 York. Available at: https://www.audubon.org/news/the-115th-christmas-bird-count-0, $718 \quad 2015)$.

719 
Extended Data Table 1. Hypotheses and explanatory variables tested for explaining the patterns in waterbird abundance changes over space and species.

\begin{tabular}{|c|c|c|c|c|}
\hline Hypotheses & Drivers & Descriptions & Explanatory variables used & Data sources \\
\hline \multirow[t]{7}{*}{$\begin{array}{l}\text { Anthropogenic } \\
\text { impacts }\end{array}$} & Surface water & $\begin{array}{l}\text { Surface water provides an essential } \\
\text { habitat for most wetland-dependent } \\
\text { species }^{1} \text {, thus its decline can } \\
\text { threaten the status of waterbirds }\end{array}$ & $\begin{array}{l}\text { Mean changes }(\%) \text { in surface } \\
\text { water occurrence between } \\
1984-1999 \text { and } 2000-2015 \text {, } \\
\text { within } 1 \mathrm{~km} \text { from each survey } \\
\text { site }\end{array}$ & $\begin{array}{l}\text { Global Surface } \\
\text { Water }^{16}\end{array}$ \\
\hline & \multirow[t]{2}{*}{ Economic growth } & \multirow{2}{*}{$\begin{array}{l}\text { Economic growth poses a threat to } \\
\text { species through habitat loss and } \\
\text { degradation but can also improve } \\
\text { environmental quality at a high } \\
\text { economic level }{ }^{56} \text {. }\end{array}$} & $\begin{array}{l}\text { Mean country-level GDP per } \\
\text { capita between } 1990 \text { and } 2010\end{array}$ & World Bank* \\
\hline & & & $\begin{array}{l}\text { Mean country-level GDP growth } \\
\text { rate (annual \%) between } 1990 \\
\text { and } 2010\end{array}$ & World Bank ${ }^{\dagger}$ \\
\hline & $\begin{array}{l}\text { Human population } \\
\text { growth }\end{array}$ & $\begin{array}{l}\text { High species extinction risk is } \\
\text { associated with high human } \\
\text { population density }{ }^{57} \text { and rapid } \\
\text { human population growth } \\
\text { h8. }\end{array}$ & $\begin{array}{l}\text { Mean changes in human } \\
\text { population density between } \\
1990 \text { and } 2000\end{array}$ & $\begin{array}{l}\text { Population } \\
\text { Density Grid } \\
\text { v3 }\end{array}$ \\
\hline & Agricultural expansion & $\begin{array}{l}\text { Farming is the biggest source of } \\
\text { threats to bird species }{ }^{60} \text {. }\end{array}$ & $\begin{array}{l}\text { Changes in crop area } \\
\text { (croplands and cropland/natural } \\
\text { vegetation mosaics) between } \\
2001 \text { and } 2010\end{array}$ & $\begin{array}{l}\text { Collection } 5 \\
\text { MODIS Global } \\
\text { Land Cover } \\
\text { Type product }^{61}\end{array}$ \\
\hline & \multirow[t]{2}{*}{ Climate change } & \multirow[t]{2}{*}{$\begin{array}{l}\text { Climate change is a strong predictor } \\
\text { of bird abundance changes }{ }^{62} \text {. }\end{array}$} & $\begin{array}{l}\text { Changes in mean Dec-Feb } \\
\text { temperature between 1985- } \\
1990 \text { and } 2005-2010\end{array}$ & $\begin{array}{l}\text { CRU TS3.10 } \\
\text { Dataset }^{63}\end{array}$ \\
\hline & & & $\begin{array}{l}\text { Changes in mean Dec-Feb } \\
\text { precipitation between 1985- } \\
1990 \text { and } 2005-2010\end{array}$ & $\begin{array}{l}\text { CRU TS3.10 } \\
\text { Dataset }^{63}\end{array}$ \\
\hline \multirow[t]{2}{*}{$\begin{array}{l}\text { Conservation } \\
\text { efforts and } \\
\text { effectiveness }\end{array}$} & Protected areas & $\begin{array}{l}\text { Waterbird abundance increased } \\
\text { more rapidly in protected than in } \\
\text { unprotected wetlands }{ }^{64,65} \text {. }\end{array}$ & $\begin{array}{l}\text { Proportion of sites covered by } \\
\text { protected areas }\end{array}$ & $\begin{array}{l}\text { World Database } \\
\text { on Protected } \\
\text { Areas }^{66}\end{array}$ \\
\hline & Governance & $\begin{array}{l}\text { Ineffective governance in a country } \\
\text { is associated with species } \\
\text { population declines }{ }^{17} \text {. }\end{array}$ & $\begin{array}{l}\text { Mean of six country-level } \\
\text { Worldwide Governance } \\
\text { Indicators between } 1996 \text { and } \\
2010\end{array}$ & World Bank ${ }^{\ddagger}$ \\
\hline \multirow[t]{3}{*}{$\begin{array}{l}\text { Species } \\
\text { characteristics }\end{array}$} & $\begin{array}{l}\text { Geographical range } \\
\text { size }\end{array}$ & $\begin{array}{l}\text { Species with small geographical } \\
\text { range may be more susceptible to } \\
\text { large-scale, stochastic threats }{ }^{67} \text {. }\end{array}$ & $\begin{array}{l}\text { Breeding/resident geographical } \\
\text { range size }\left(\mathrm{km}^{2}\right)\end{array}$ & $\begin{array}{l}\text { Birdlife Data } \\
\text { Zone }^{\S}\end{array}$ \\
\hline & Migratory status & $\begin{array}{l}\text { Migratory species can be affected } \\
\text { by conditions at multiple locations, } \\
\text { thus tend to show population } \\
\text { declines }^{68,69} \text {. }\end{array}$ & Migrant or non-migrant & $\begin{array}{l}\text { Birdlife Data } \\
\text { Zone }\end{array}$ \\
\hline & Body size & $\begin{array}{l}\text { Body size is a strong predictor of } \\
\text { bird abundance changes }{ }^{70} \text { but its } \\
\text { association with bird extinction risk } \\
\text { can be both positive and negative, } \\
\text { depending on threats to the } \\
\text { species }^{71}\end{array}$ & Body mass (g) & EltonTraits $1.0^{72}$ \\
\hline
\end{tabular}

* http://data.worldbank.org/indicator/NY.GDP.PCAP.KD

${ }^{\dagger}$ http://data.worldbank.org/indicator/NY.GDP.MKTP.KD.ZG

$\$$ http://data.worldbank.org/data-catalog/worldwide-governance-indicators

${ }^{\S}$ http://datazone.birdlife.org/home 
Extended Data Table 2. Correlation matrix (Spearman's rank correlation) of nine

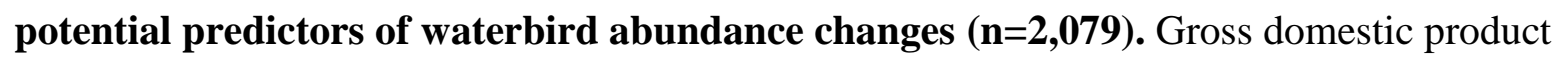

(GDP) per capita is $\log _{10}$-transformed values. Strong correlation $(|r|>0.7)$ are shown in bold.

\begin{tabular}{|c|c|c|c|c|c|c|c|c|}
\hline & $\begin{array}{l}\text { GDP per } \\
\text { capita }\end{array}$ & $\begin{array}{l}\text { Water } \\
\text { change }\end{array}$ & $\begin{array}{l}\text { GDP } \\
\text { growth rate }\end{array}$ & $\begin{array}{l}\text { Human } \\
\text { population } \\
\text { change } \\
\end{array}$ & $\begin{array}{l}\text { Crop area } \\
\text { change }\end{array}$ & $\begin{array}{l}\text { Dec-Feb } \\
\text { temperature } \\
\text { change }\end{array}$ & $\begin{array}{l}\text { Dec-Feb } \\
\text { precipitation } \\
\text { change }\end{array}$ & $\begin{array}{l}\text { Protected area } \\
\text { coverage }\end{array}$ \\
\hline Water change & -0.087 & & & & & & & \\
\hline GDP growth rate & -0.502 & 0.003 & & & & & & \\
\hline $\begin{array}{l}\text { Human population } \\
\text { change }\end{array}$ & -0.326 & -0.047 & 0.442 & & & & & \\
\hline Crop area change & -0.095 & 0.039 & 0.208 & 0.140 & & & & \\
\hline $\begin{array}{l}\text { Dec-Feb temperature } \\
\text { change }\end{array}$ & -0.176 & -0.070 & 0.158 & 0.100 & -0.087 & & & \\
\hline $\begin{array}{l}\text { Dec-Feb precipitation } \\
\text { change }\end{array}$ & 0.005 & 0.045 & -0.059 & -0.043 & -0.091 & 0.031 & & \\
\hline $\begin{array}{l}\text { Protected area } \\
\text { coverage }\end{array}$ & 0.002 & 0.002 & -0.225 & -0.077 & -0.051 & -0.121 & -0.081 & \\
\hline Governance & 0.755 & -0.100 & -0.547 & -0.344 & -0.169 & -0.200 & -0.086 & 0.047 \\
\hline
\end{tabular}




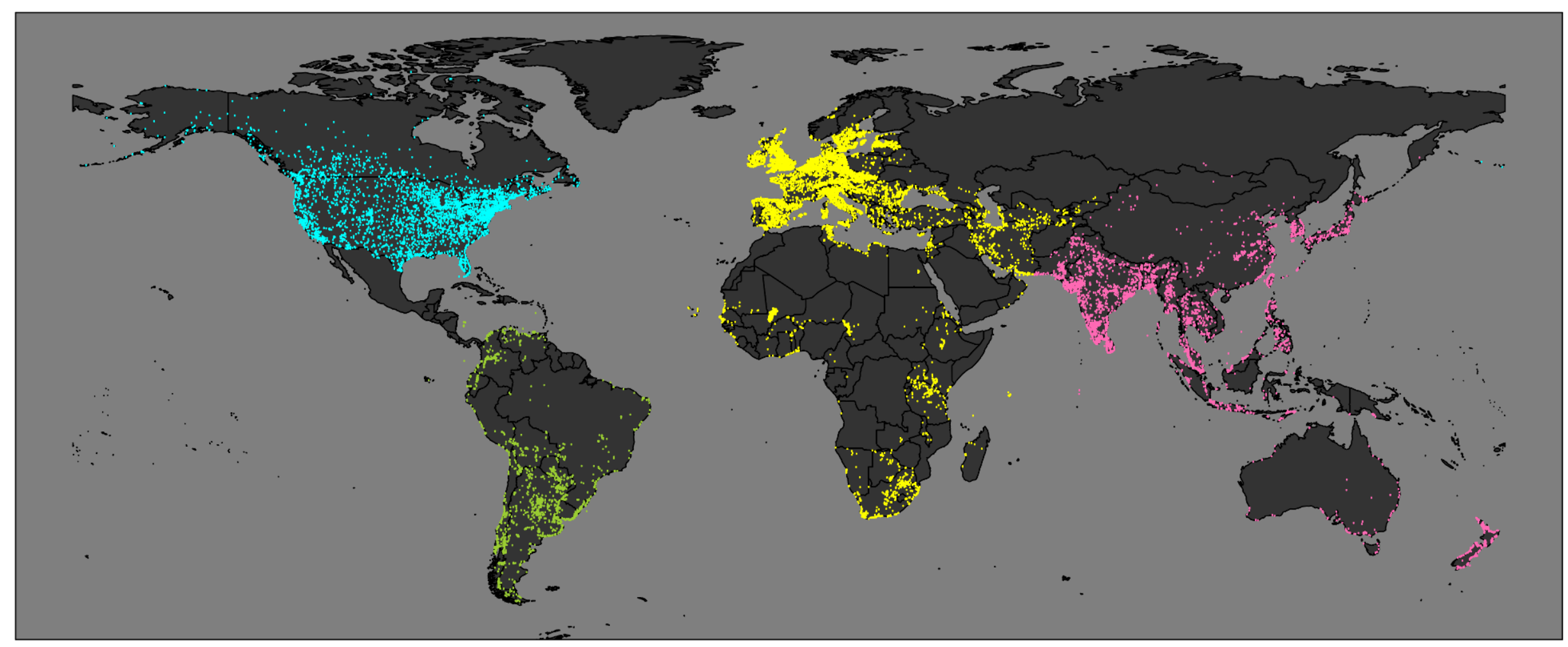

Extended Data Fig. 1. The distribution of all the 25,769 survey sites used in the analyses. Sites for the International Waterbird Census are shown in yellow (African-Eurasian Waterbird Census), pink (Asian Waterbird Census) and green (Neotropical Waterbird Census) and those for the Christmas Bird Count are in cyan. 


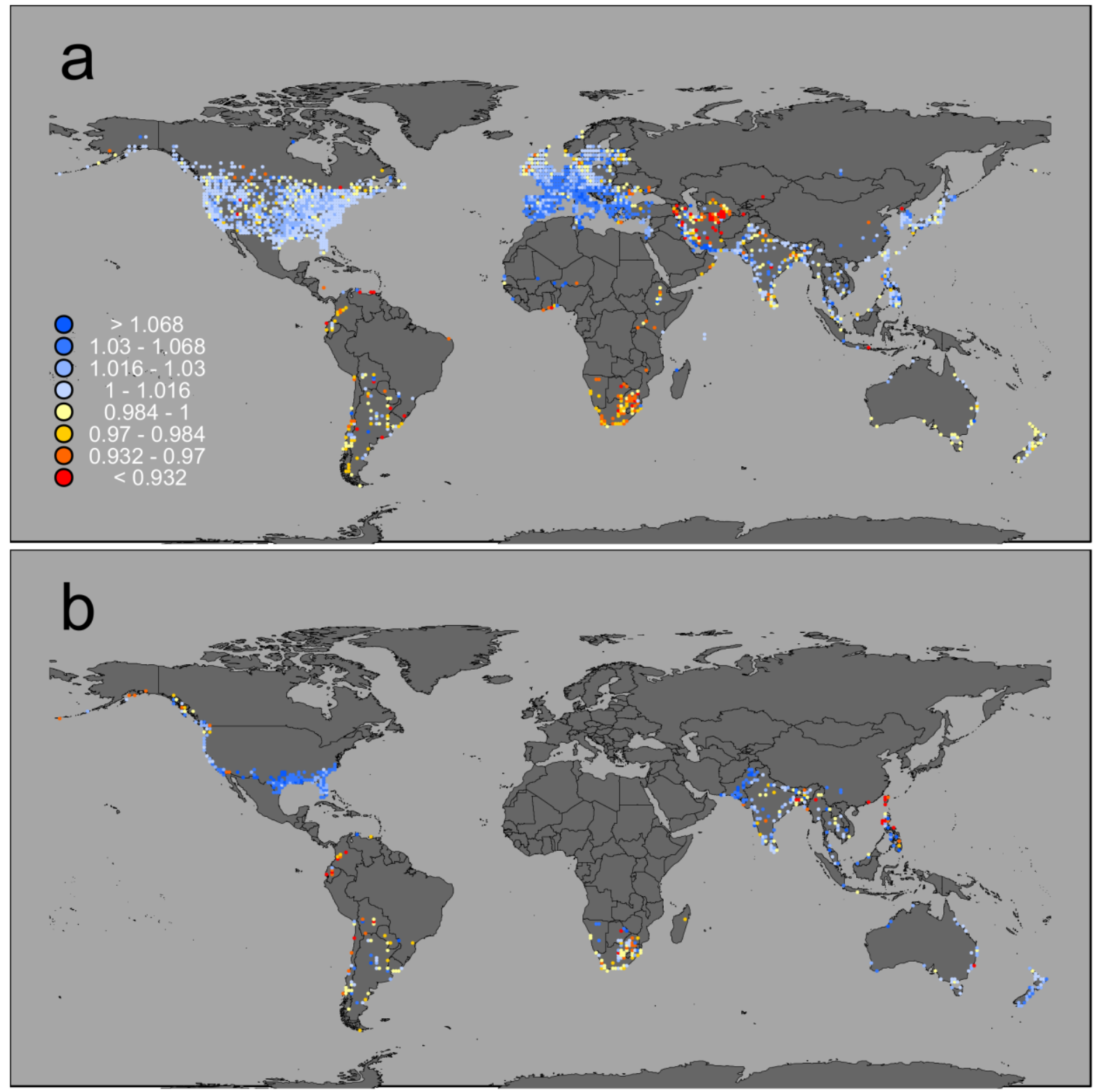

Extended Data Fig. 2. Global distribution of mean annual changes in abundance across

(a) 373 migratory and (b) 88 non-migratory waterbird species (i.e., community-level changes). Migratory status of each species is from the BirdLife Data Zone (see Methods for more detail). 

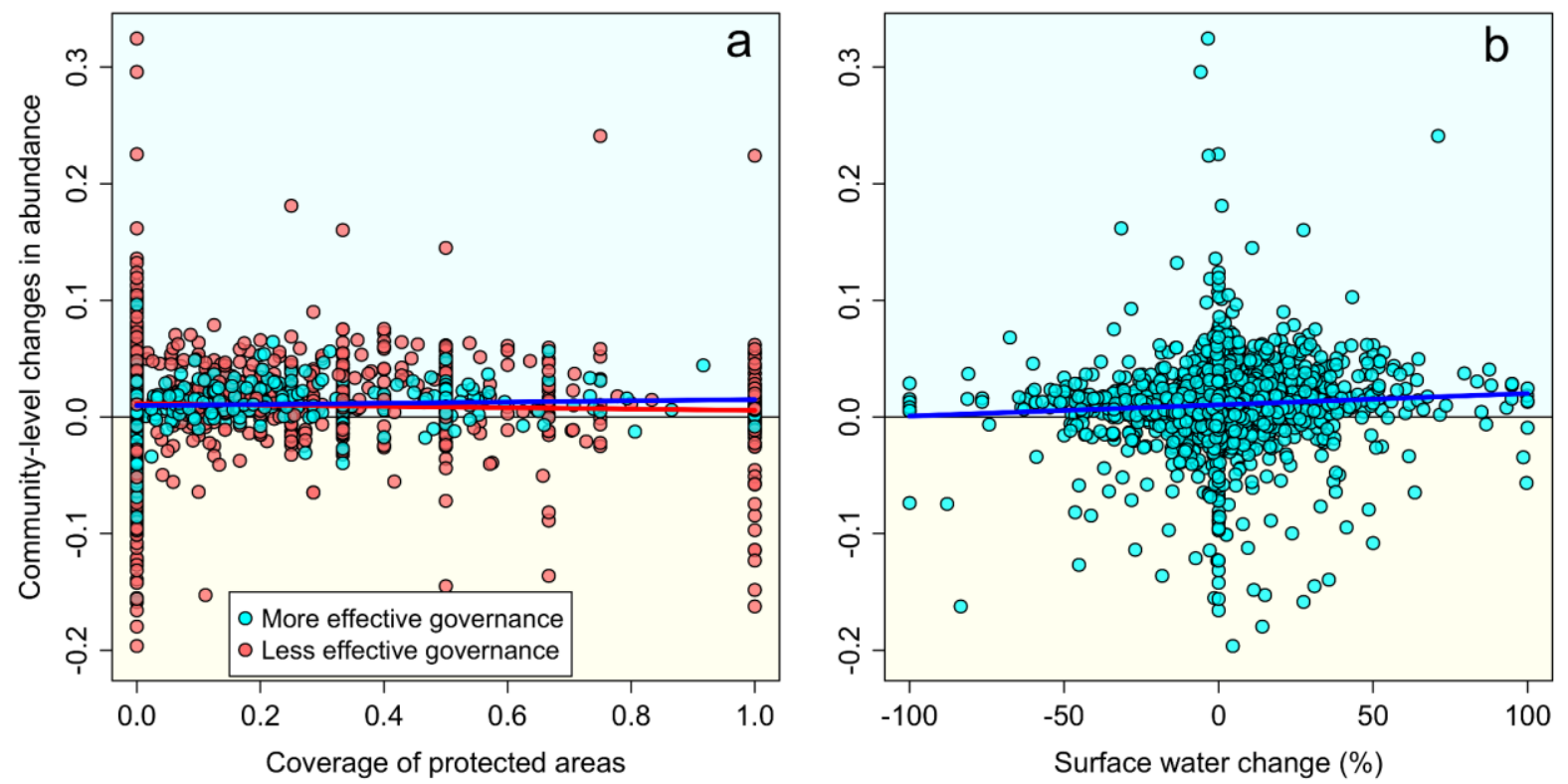

Extended Data Fig. 3. Relationships between community-level changes in abundance and (a) the proportion of sites covered by protected areas and (b) surface water change $(\mathbf{n = 2 , 0 7 9 ) . ~ R e g r e s s i o n ~ l i n e s ~ b a s e d ~ o n ~ t h e ~ e s t i m a t e d ~ c o e f f i c i e n t s ~ i n ~ F i g . ~ 3 a ~ a r e ~ a l s o ~ s h o w n ; ~}$ values and regression lines for species in areas with more and less effective governance are shown in blue and red, respectively. 


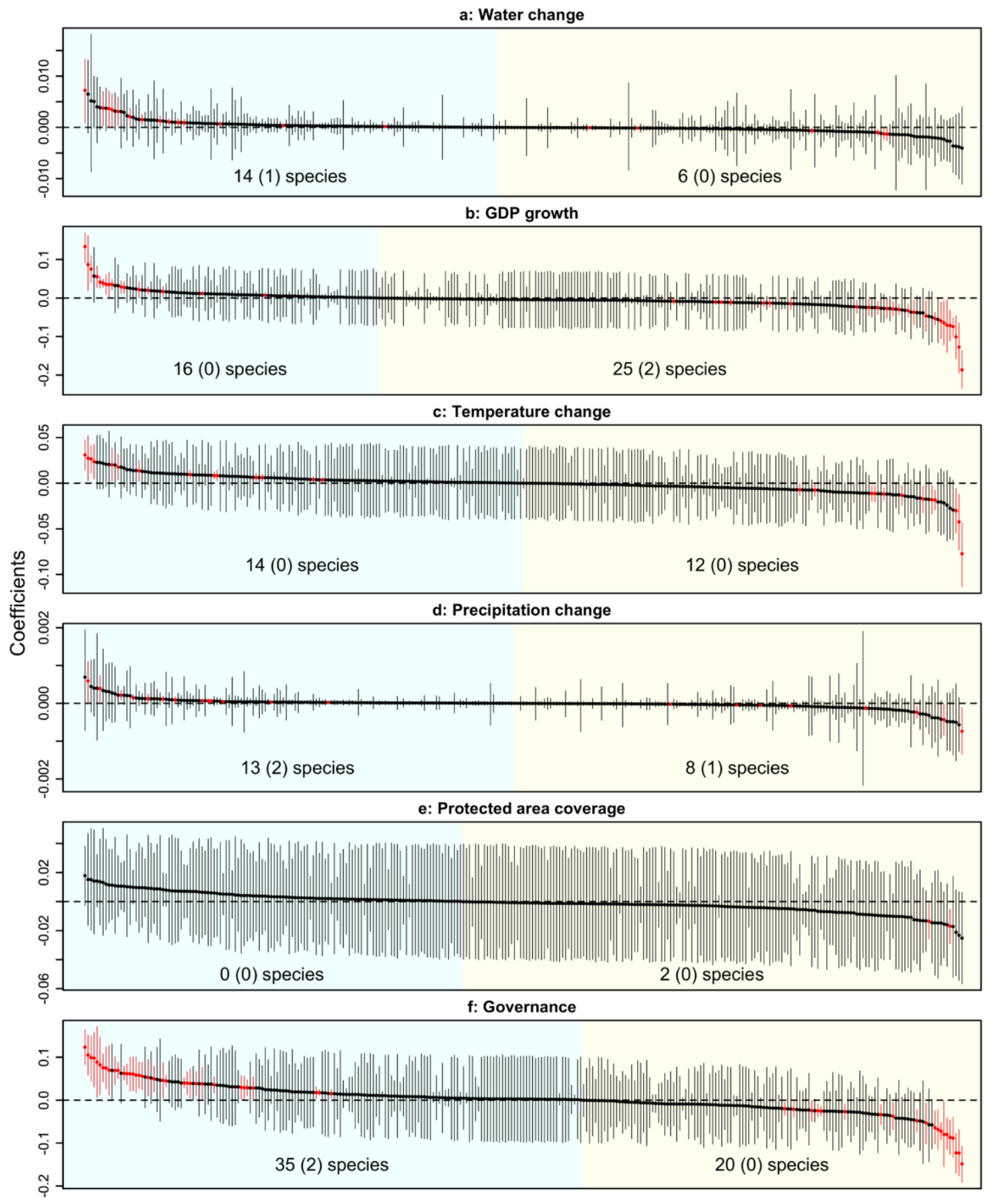

Extended Data Fig. 4. Effects of five hypothesised predictors (see Extended Data Table 1

for more detail) on population-level changes in abundance. In each panel, the medians and 95\% credible intervals of the estimated coefficients for 293 species are shown in order of decreasing positive effect size from the left (those with 95\% credible intervals not overlapping with zero shown in red). The numbers of species with significant positive and negative coefficients are also shown, with the number of non-migratory species in parentheses. 

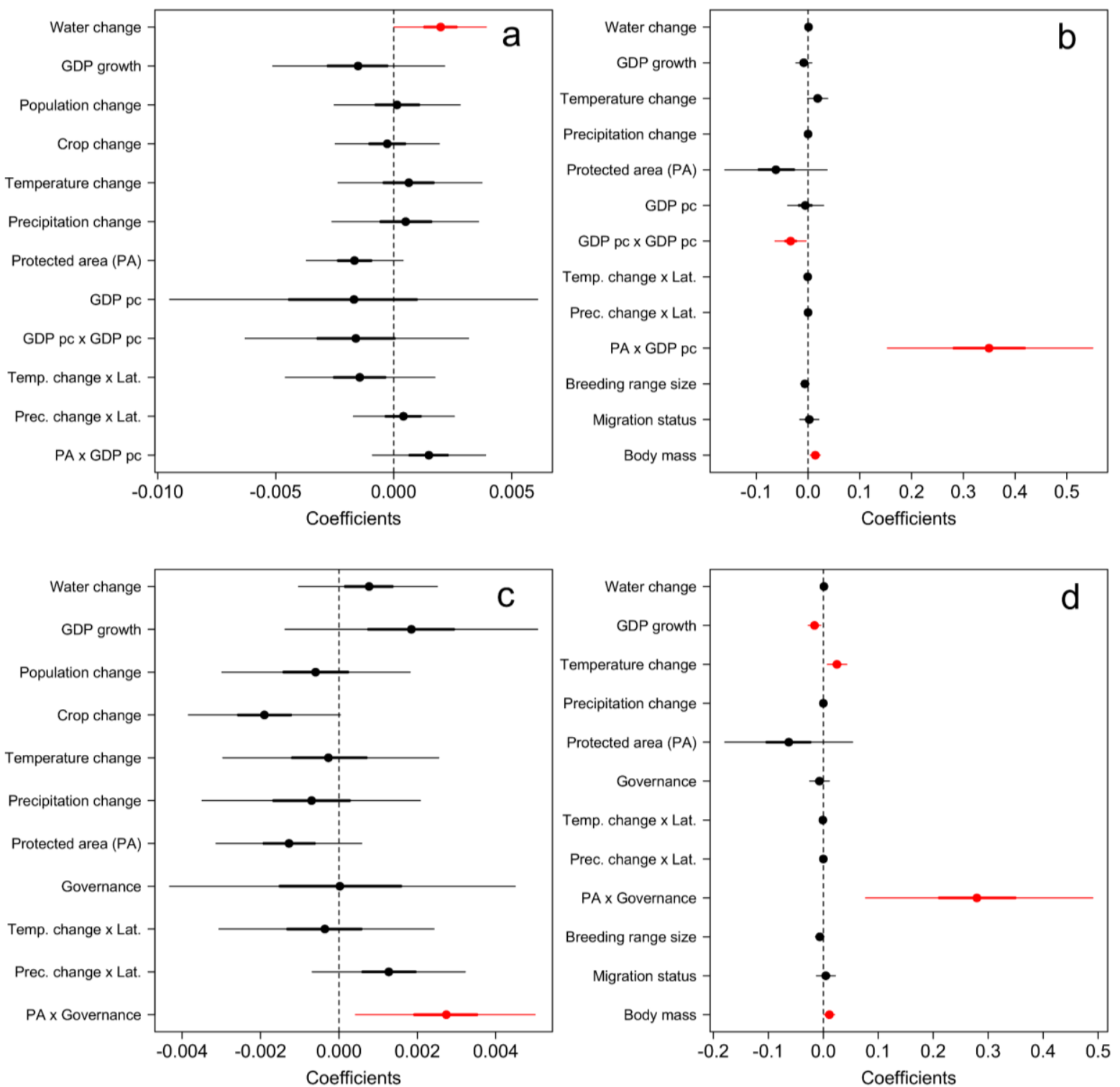

Extended Data Fig. 5. Sensitivity of results to the correlation between governance and gross domestic product (GDP) per capita and designation years of protected areas.

Estimated coefficients in the multivariate analysis of (a) community-level $(n=2,079)$ and (b) species-level changes in abundance (based on 293 species; see Supplementary Data S2 for the number of grid cells in each species), where governance was replaced with linear and quadratic terms of GDP per capita, and (c) community-level ( $n=2,079)$ and (d) species-level changes in abundance (based on 293 species; see Supplementary Data S2 for the number of grid cells in each species), where only protected areas known to have been designated before 1990 (the first survey year in our dataset) were used in the most conservative approach.

Posterior medians with $95 \%$ and $50 \%$ (thick lines) credible intervals are shown. Coefficients with $95 \%$ credible intervals not overlapping with zero are shown in red. 

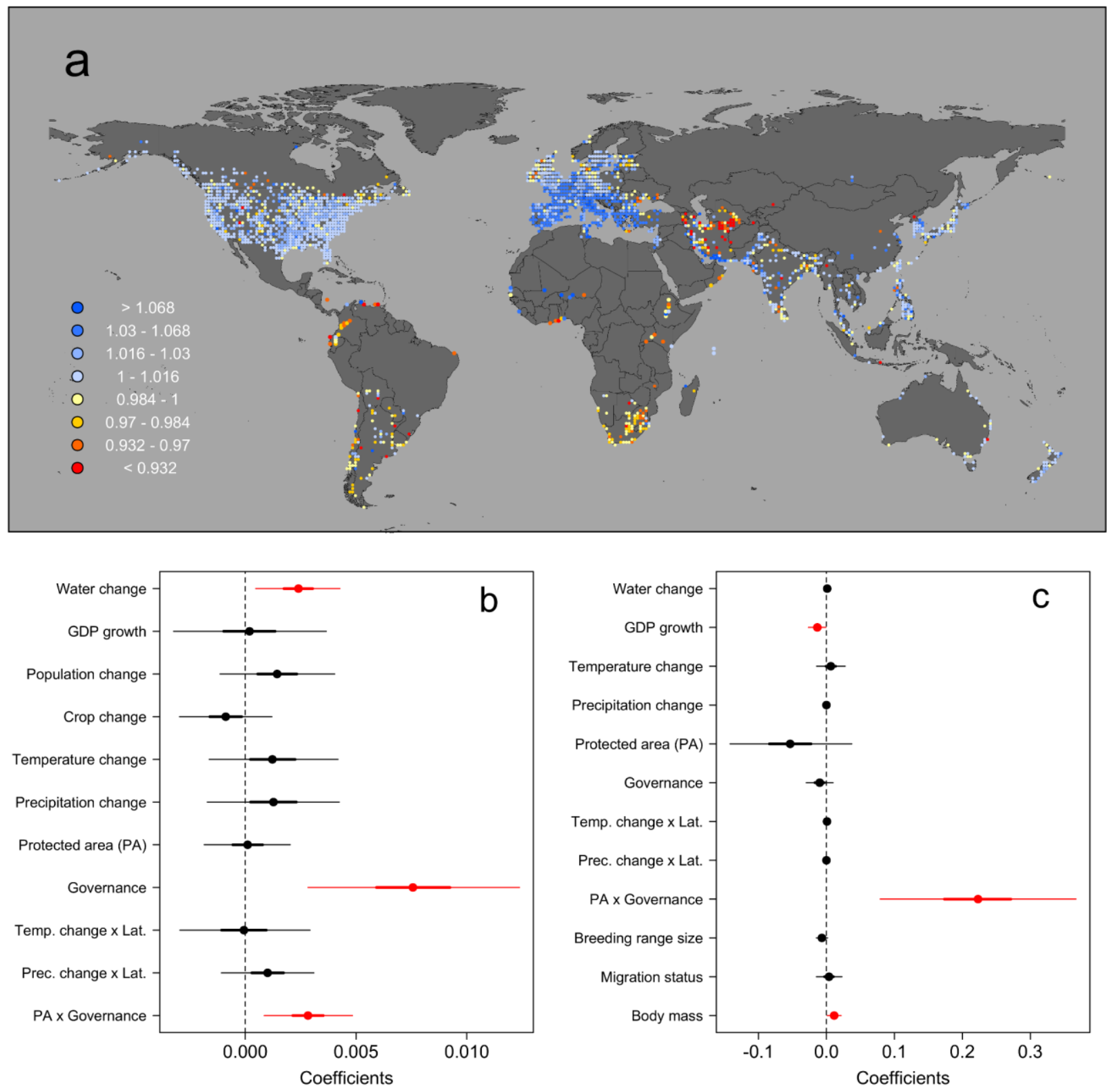

Extended Data Fig. 6. Sensitivity of the results to the inclusion of seabird species. (a)

Global distribution of mean annual changes in abundance across 447 waterbird species excluding the 14 seabird species between 1990 and 2013. Estimated coefficients in the multivariate analysis of (b) community-level $(n=2,079)$ and (c) species-level changes in abundance, where the 14 seabird species were excluded (i.e., based on 447 species; see Supplementary Data S2 for the number of grid cells in each species). Posterior medians with 95\% and 50\% (thick lines) credible intervals are shown. Coefficients with 95\% credible intervals not overlapping with zero are shown in red. 

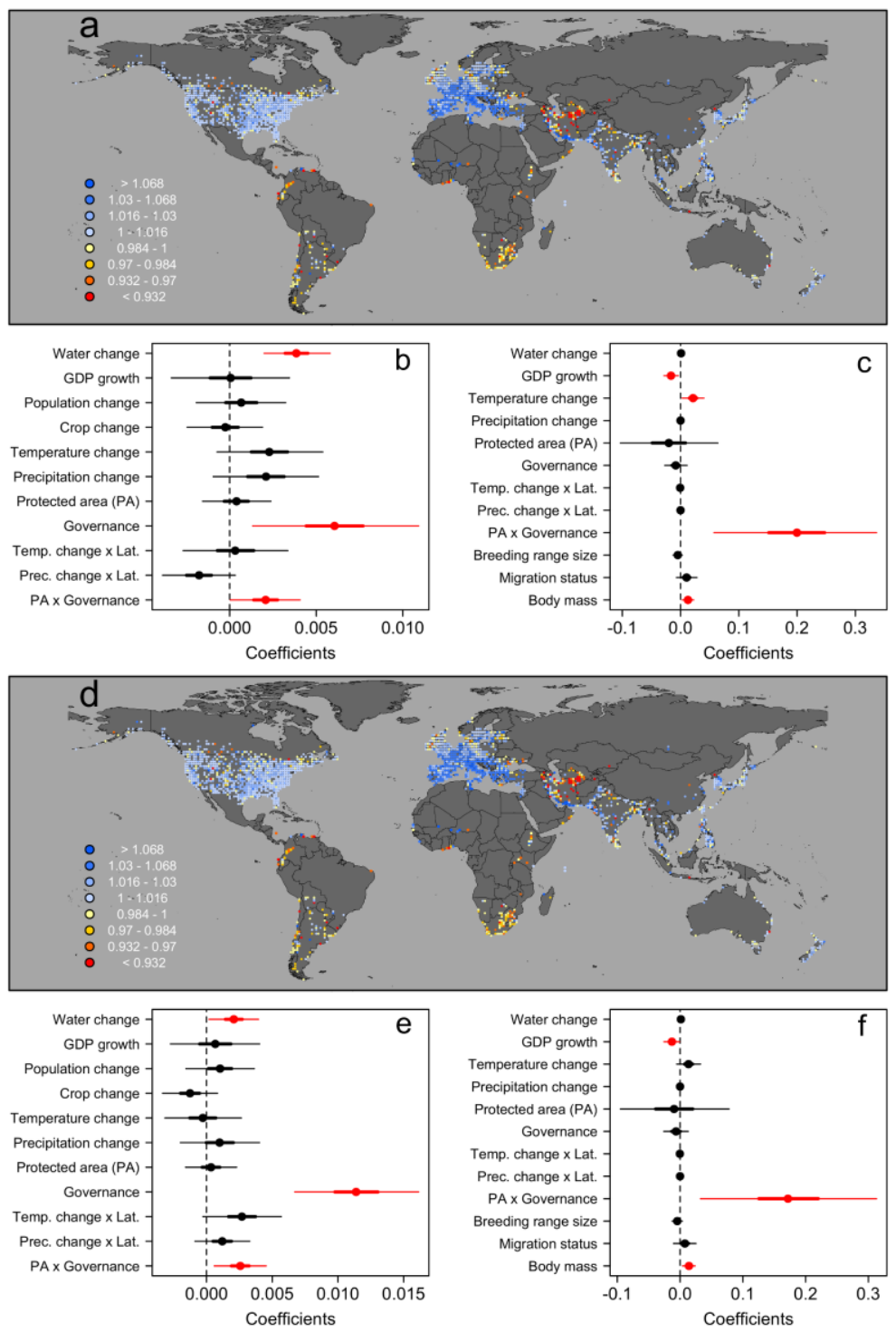

Extended Data Fig. 7. Sensitivity of the results to the choice of Christmas Bird Count (CBC) survey sites for the analyses. (a) Global distribution of mean annual changes in abundance across 461 waterbird species between 1990 and 2013 after excluding 41 CBC grid cells with neither landscape-scale wetland areas nor local-scale surface water occurrences (within $1 \mathrm{~km}$ of all the survey sites included). Estimated coefficients in the multivariate analysis of (b) community-level $(n=2,038)$ and (c) species-level changes in abundance (based on 293 species), where 41 CBC grid cells with neither landscape-scale wetland areas nor local-scale surface water occurrences (within $1 \mathrm{~km}$ of all the survey sites) were excluded. (d) Global distribution of mean annual changes in abundance across 461 waterbird species between 1990 and 2013 after excluding eight CBC grid cells where the proportion of urban areas was over 0.3. Estimated coefficients in the multivariate analysis of (e) community-level ( $n=2,071)$ and (f) species-level changes in abundance (based on 293 species), where eight CBC grid cells with a proportion of urban areas of over 0.3 were excluded. Posterior medians with $95 \%$ and $50 \%$ (thick lines) credible intervals are shown. Coefficients with $95 \%$ credible intervals not overlapping with zero are shown in red. 


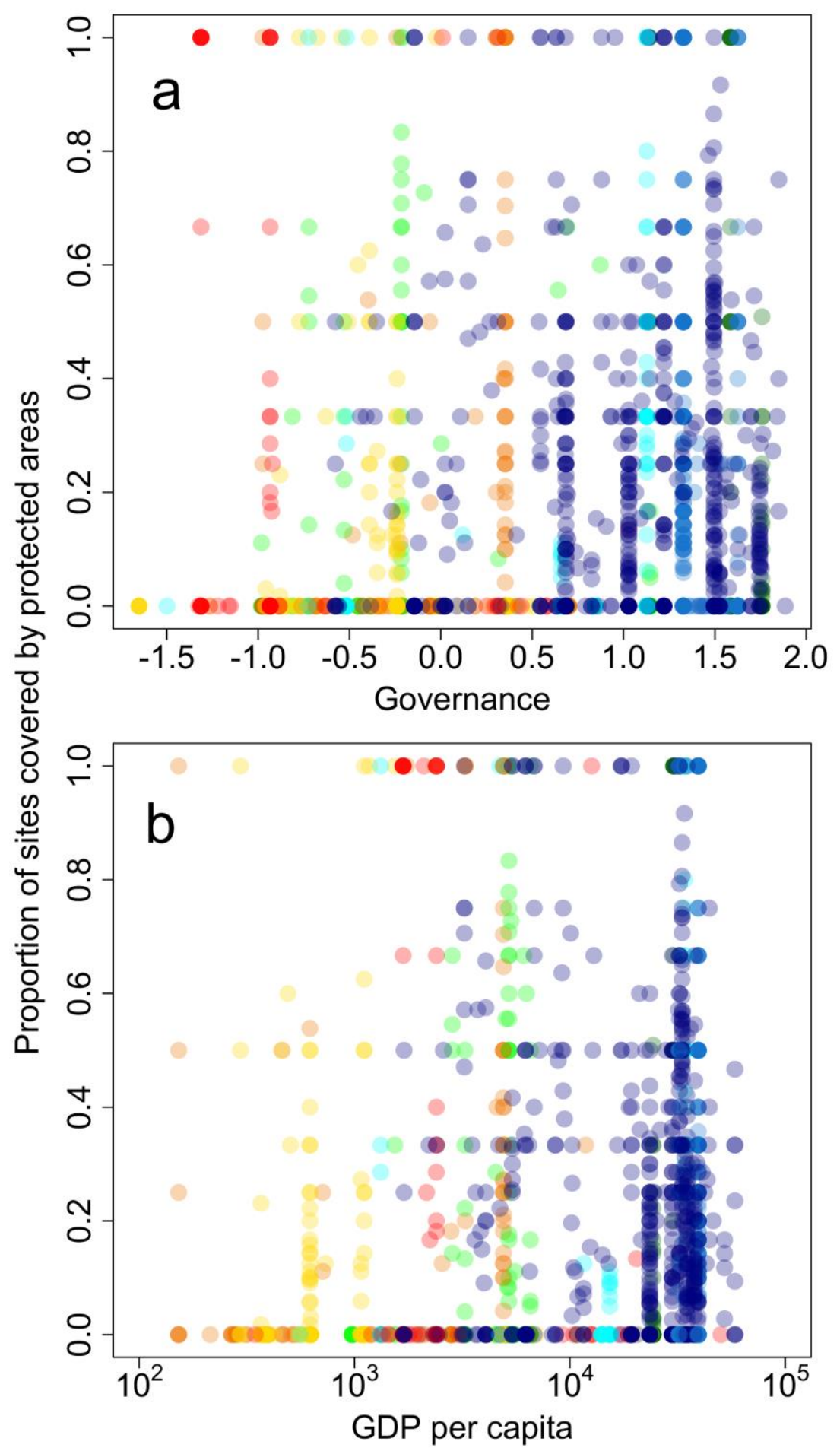

Extended Data Fig. 8. Relationships between the proportion of sites covered by protected areas and (a) governance and (b) gross domestic product (GDP) per capita.

Colors indicate regions: blue: North America, green: South America, navy: Europe, orange: Africa, red: Western/Central Asia, yellow: South/Southeast Asia, cyan: East Asia and Russia, and dark green: Oceania. 